\title{
The Applications and Complexity Analysis Based on Network Embedding Behaviors under Evolutionary Game Framework
}

\author{
Xin Su $\mathbb{D}^{1,2}$ Hui Zhang, ${ }^{1}$ and Shubing Guo $\mathbb{1}^{3}$ \\ ${ }^{1}$ Shandong University of Finance and Economics, School of Business Administration, Jinan 250014, China \\ ${ }^{2}$ Research Center of Government Performance Evaluation of Shandong University of Finance and Economics, \\ Jinan 250002, China \\ ${ }^{3}$ College of Management and Economics, Tianjin University, Tianjin, China \\ Correspondence should be addressed to Xin Su; sdcjsx2016@126.com and Shubing Guo; sbguo20160831@126.com
}

Received 10 March 2020; Revised 13 April 2020; Accepted 22 April 2020; Published 15 June 2020

Academic Editor: Abdelalim Elsadany

Copyright ( 2020 Xin Su et al. This is an open access article distributed under the Creative Commons Attribution License, which permits unrestricted use, distribution, and reproduction in any medium, provided the original work is properly cited.

\begin{abstract}
In this paper, we use the dynamic mechanism of biological evolution to simulate the enterprises' bounded rational game. We construct game models of network embedding behaviors of horizontal and vertical enterprises in supply chain, explain the repeated games of random pairs of enterprises by replication dynamic differential equations, study the characteristics and evolution trend of this flow, conduct simulation experiments, clarify the evolution direction and law of network embedding strategy selection of supply chain enterprises, and discuss the stable state of evolutionary game and its dynamic convergence process. The results show that the probability of supply chain enterprises choosing a network embedding strategy is related to the enterprises' special assets investment cost, cooperation cost, network income, and cooperation benefits. Supply chain enterprises should reduce the special assets investment cost and cooperation cost, maximize network income and cooperation income, narrow the gap between the extra-cooperation profit and the current cooperation profit, and restrain them from violating cooperation contracts or taking opportunistic actions.
\end{abstract}

\section{Introduction}

With the rapid development in science and technology, the product life cycle is shortening day by day, and the uncertainty of the external market environment that enterprises are facing is getting higher and higher. It is difficult for enterprises to cope with the competitive market environment solely by their own resources endowment. In order to alleviate the adverse effects of resource constraints on the enterprises sustainable growth and strengthen their core competitive advantages, enterprises must break through their inherent boundaries or frameworks [1], establish stable cooperative relations with upstream and downstream enterprises, and form their own supply chain networks. Therefore, the competition among enterprises is no longer the independent competition among individual enterprises but the competition between supply chains and supply chains [2].
By embedding in a certain supply chain network and signing cooperative contracts with other member enterprises, enterprises can build cooperative partnerships, which is helpful to realize the resources and interests sharing among enterprises, and then improve the performance [3]. The supply chain network mainly includes suppliers, manufacturers, wholesalers, distributors, and retailers and other participants. They cooperate closely with each other in order to cultivate the overall competitive advantage and achieve a win-win situation $[4,5]$. Generally speaking, the manufacturers occupy the important position as the core enterprises of the supply network. On the one hand, the manufacturers and upstream suppliers establish cooperative relations to obtain raw materials needed by the enterprises and improve the production efficiency and performance on the basis of the specialized division [6]. On the other hand, manufacturers sign cooperative contracts with downstream distributors or retailers to expand sales channels, so as to 
transfer products to consumers smoothly through intermediaries, and ultimately maximize the products value and obtain network rent or excess profits [7].

Previous studies have mostly discussed the game equilibrium of supplier-manufacturer or manufacturer-distributor relationship and benefit distributions in the static supply chain [8]. They have qualitatively analyzed the supply chain relationship governance concept, connotation, and countermeasures $[9,10]$ or empirically studied the impacts of supply chain partnership quality, information sharing, logistics capability, joint liability governance and other factors on supply chain enterprise behaviors, supply chain integrations, operational efficiency, and performance [11-13]. However, in view of the whole supply chain, there are few literatures on the evolutionary game of enterprises' network embedding behavior in the dynamic environment, so it is difficult to effectively reflect the specific operation practice of the supply chain embedded in the dynamic environment. As a complex system composed of node enterprises, each node enterprise is an independent legal person with different resource endowments and business objectives. There are differences and conflicts in weighing the benefits and costs of cooperation, which are embodied in the rational choice and cooperation of whether each node enterprise is embedded in the supply chain network. The key to solve the above problems is to build the evolutionary game model of the network embedding behaviors of supply chain enterprises. Analyzing the influencing factors of the enterprises' network embedding behaviors and clarifying their rational choices are conducive to the sustainable development of the cooperation relationship between supply chain enterprises and the improvement of the supply chain operation ability. Therefore, in view of the fact that dynamics and complexity are the essential features of supply chain relationship network, this paper constructs evolutionary game models between supply chain participants from a systematic and dynamic perspective, discusses the characteristics and evolution trend of this flow, seeks the interests joint point of each participant in supply chain cooperation so as to maintain cooperation stability, and provides a reference basis for improving the enterprises' performance.

\section{Reviews}

2.1. The Definition of Supply Chain Network. A supply chain is a complex adaptive system, which refers to a logistics process around core enterprises from raw material procurement and intermediate processing to final product and product transfer to consumers, thus realizing product values $[14,15]$. Supply chain is a functional network composed of suppliers, manufacturers, distributors, retailers, and consumers. And it is manifested as logistics, capital flow, and information flow, which can meet customer needs through the transfer between enterprises or functional departments, so as to maximize profits [16]. The standard logistics terminology published in China in 2011 defines the supply chain as the network structure formed by upstream and downstream enterprises that provide products and services to end-users in the production process. Some scholars also put forward that supply chain is a learning system for knowledge sharing among enterprises in the whole chain: an important way for enterprises to acquire external knowledge and an important source for enterprises to win competitive advantage. In addition, through this learning system, enterprises can better share information, obtain more external heterogeneous knowledge, improve the supply chain operation capability, and form competitive advantages that are difficult to be replaced [17]. From the complex relationship between knowledge management and supply chain management, supply chain is not only material supply chain but also "knowledge supply chain" or "knowledge supply and demand network."

The supply chain network is a kind of network organization between the market system and vertical integration. The suppliers, manufacturers, distributors, and retailers in the network form certain transaction links, share resources, and information and cooperate to strengthen the supply chain overall competitive advantage by signing contracts $[11,18]$. In China, enterprises are more represented as economic legal persons, referring to commodity producers, operators, or economic organizations that rely on their fixed production and operation sites, funds, equipments, and employees to engage in production, processing, and service activities in order to maximize profits. The enterprises operate independently and take responsibility for their own profits and losses [19]. Based on the supply chain characteristics and enterprises concept, this paper considers that the member enterprises in supply chain network that meet the enterprises' attributes can be collectively known as supply chain enterprises, such as suppliers, manufacturers, distributors, and retailers. Each supply chain enterprise makes full use of its own superior resources and capabilities interdependently and complementarily and ultimately achieves the objectives and value increment of each link of the supply chain. Enterprise executives have long been concerned about the mechanism of complexity on enterprise operation and committed to taking measures to weaken its negative impact. Supply chain complexity is recognized as an important challenge for enterprises [20]. With the continuous enrichment of economic activities, the supply chain network complexity is getting higher and higher. The complex supply chain network is gradually replacing the simple traditional supply network structure [21, 22].

2.2. Network Embedding Theory. Polanyi first puts forward the word "embeddedness" in his book "great change" and considers that "embeddedness" belongs to the category of economic sociology [23]. The enterprises' economic behavior is embedded in certain social relations, and enterprises and external social environment interact with each other. Subsequently, the viewpoint of "embeddedness" was gradually integrated into social network research, mainly exploring the specific manifestations of enterprises' economic behaviors in social networks. Granovetter held that the path of social relations influencing enterprise behaviors and institutions is one of the classical problems of social theory. In the relevant literature, it further reveals the influence of "embeddedness" among enterprises on enterprises' economic behaviors, marketing channels, cooperative 
relations, organizational adaptability, and market positioning decision-making in the context of network. The embedding viewpoint focuses on the roles of specific interpersonal relationships. And it holds that enterprises' structure plays an important role in stimulating the subject's trust perception and preventing misconduct [24]. In addition, Uzzi believed that the study of "embeddedness" is conducive to deepening the understanding of the impact mechanism of social structure on economic life. Therefore, the term "embeddedness" has become a hot research topic in the field of sociology and economics. It is of obvious characteristics such as time economy, comprehensive consistency, and complex adaptability in improving allocation efficiency [25].

The generation mechanism of "embeddedness" originates from the trust level among the member enterprises in the network. Based on the enterprises' mutual trust, each enterprise embeds its own economic behavior into the social network, which gradually forms a more stable relationship $[26,27]$, and realizes the resources and information sharing in the network $[28,29]$. Network embedding includes the social network relationship and trust relationship formed by emotional interaction among members of the network [30]. And network embedding contains the more formal network relationship such as enterprise alliance and franchise [31]. Cluster enterprises, supply chain enterprises, or enterprises with cooperative relationships will exchange business, resources, and information with other enterprises and then build an interdependent social network relationship. The member enterprises in the network have changed from the original single or binary relationship to the interdependent multirelationship or network relationship [32, 33]. To a certain extent, this is conducive to the rapid flow and efficient transformation of resources and information in the network. Among them, the enterprises exist in the form of network "nodes," while the "edges" of the social relationship network represent the social relations formed by the transaction links among the enterprises [7, 34-37].

Therefore, network embedding behavior refers to the form of a transaction or cooperated network established by an enterprise because of its future development, transaction, or the need to cope with competitive pressures. The purpose is to achieve resource sharing and value creation in the network. As a supply-demand network organization, the relationship between the supply chain upstream and downstream nodes is mainly manifested as relational transactions. The members embedded in the network can realize feedback more quickly and clearly and obtain new solutions. For the dynamic system of the supply chain, network embedding is mainly manifested in the supply and demand network formed by the upstream and downstream enterprises based on trust or contract. Within this network, each node enterprise plays a synergistic effect and ultimately improves the supply chain operation capability on the basis of realizing resource, information exchange, and sharing.

2.3. Reviews of Supply Chain Enterprise Game. However, as a complex system, each node enterprise has differences and conflicts in balancing the cooperation benefits and costs. In order to maximize their own interests and operate the supply chain efficiently, each node enterprise keeps playing repeated games. Based on different research perspectives, the relevant scholars discussed the game problems of supply chain operation. For example, Li thinks that the efficient operation of supply chain is the result of many factors. By constructing the game model of supply chain node enterprise strategic partner collaborative competition, the paper analyzes the important factors that affect the realization of supply chain cooperative game [38]. Nie et al. builds a supply chain model with fairness-concerns based on Stackelberg game, discusses the decision-making and coordination of the supply chain, analyzes the impact of the disagreement points on supply chain operation, and thinks that enterprises should adopt the way of price subsidy to design the joint contract to promote the coordination of the supply chain [39]. Sun uses the evolutionary game model to explore the rules and dynamic change process of $\mathrm{B} 2 \mathrm{C}$ service enterprises' collaborative cooperation under the e-commerce platform based on the perspective of enterprise benefit distribution and puts forward countermeasures to improve the supply chain operation capability [40]. Jian et al. establishes a green supply chain game model in which manufacturers consider both profit and environmental objectives and explores the operation and cooperation strategies of different objectives at the supply chain level [41]. In addition, Jian et al. examines the contract coordination among manufacturers with peer-induced and distributional fairness concerns, constructs two game models, and analyzes the influence of a revenue sharing contract on the pricing decisions and profit distribution of a competitive supply chain considering fairness concerns [42].

It can be seen that most of the existing researches are based on different perspectives, using evolutionary game method to discuss the supply chain operation, but not involving the game of enterprise network embedding behavior, and exploring the synergistic effect of multiple factors on the enterprise network embedding behavior choice. In view of this, this paper constructs the game model of network embedding behavior of supply chain enterprises, discusses the influence of the factors such as the investment cost of special assets, cooperation cost, network income, and cooperation income on the supply chain operation, analyzes the stable state and dynamic convergence process of evolutionary game, and provides theoretical reference for the enterprises' decision-making of network embedding behavior and the maintenance of cooperation relationship.

\section{Evolutionary Game Analysis of Enterprises' Embedding Behaviors}

In the supply chain network, there are not only horizontal cooperative behaviors among parallel participants but also vertical cooperative behaviors between upstream and downstream enterprises [35]. It is assumed that, in the supply chain network, each participant is a bounded rational economic person with independent decision-making ability. The purpose of cooperation with upstream and downstream enterprises or horizontal enterprises is to maximize economic benefits. The cooperative behaviors among enterprises in the supply chain network are shown in Figure 1. 


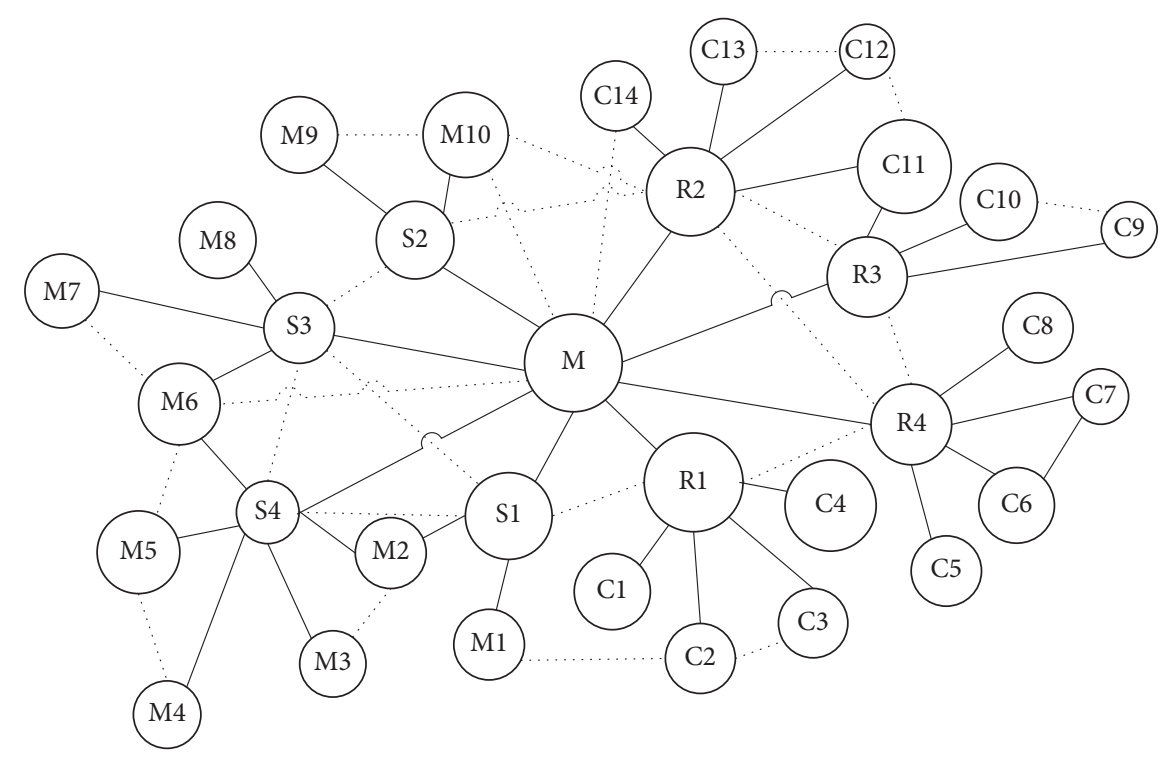

FIgURE 1: Supply chain relationship network.

The nodes represent supply chain enterprises. The supplier nodes are represented by the letter "S," the manufacturer nodes are represented by the letter "M," the retailer nodes are represented by the letter " $R$," and the consumers are represented by the letter "C." The solid line represents the established cooperation relationship between supply chain enterprises, while the dotted line indicates the potential cooperation relationship between the two enterprises. By embedding in a supply chain network, an enterprise will sign a cooperative contract with other member enterprises to share resources in order to improve the performance. All cooperation between $\mathrm{S}$ and $\mathrm{S}, \mathrm{M}$ and $\mathrm{M}$, and $\mathrm{R}$ and $\mathrm{R}$ are known as supply chain enterprises horizontal cooperation, while all cooperation between $S$ and $M, S$ and $R$, and $M$ and $S$ are called supply chain enterprises vertical cooperation. Enterprises can broaden the channels of accessing resources, so as to obtain more heterogeneous resources and information, reduce transaction costs, and ultimately enhance the production efficiency through embedding in a supply chain network.

\subsection{Evolutionary Game Analysis of Horizontal Enterprises.} Horizontal enterprise cooperative behavior in a supply chain network is mainly manifested in the parallel cooperative relationship or behavior between suppliers and suppliers, manufacturers and manufacturers, or retailers and retailers. Through joint production or R\&D, enterprises can enhance their innovation capability and output level.

3.1.1. Model Building. Assuming that an enterprise has the independent decision-making power to embed in supply chain relationship networks, enterprise A and enterprise B are both horizontal enterprises, and their strategy space is (embedding, nonembedding). The choice of embedding strategy means that enterprises choose to cooperate with other members of the supply chain network to form an alliance relationship. On the one hand, enterprises can obtain heterogeneous resources and information needed for the development of enterprises by embedding in the relationship network. These resources and information can be further transformed into social capital or relational capital of enterprises. This paper calls them network gains. On the other hand, enterprises can cooperate with other member enterprises to realize the sharing of information and resources and then obtain cooperative gains. If both enterprises $A$ and enterprise $B$ adopt the embedding strategy, it indicates that there is a cooperative relationship between enterprise $A$ and enterprise $B$, which can generate certain cooperation benefits. In addition, the probability of embedding strategy is $x(0<x<1)$ and the probability of nonembedding strategy is $(1-x)$. The total income of an enterprise is the sum of the income from independent production or sales and the income from cooperation.

(1) Enterprise A adopts the embedding strategy, while enterprise B also adopts the embedding strategy, which means that there is a cooperative relationship between enterprise A and enterprise B. Enterprises A and $B$ need to spend some energy or invest some assets when they choose to embed the supply chain relationship network; that is, the investment cost of special assets is $C_{\mathrm{A} 0}\left(C_{\mathrm{A} 0}>0\right)$ and $C_{\mathrm{B} 0}\left(C_{\mathrm{B} 0}>0\right)$, respectively, so as to obtain network income $R_{\mathrm{A} 0}\left(R_{\mathrm{A} 0}>0\right)$ and $R_{\mathrm{B} 0}\left(R_{\mathrm{B} 0}>0\right)$. In addition, when enterprise $A$ and enterprise $B$ form a contractual relationship and cooperation, they need to invest a certain time cost and transaction cost; that is, the cooperation cost of enterprise $\mathrm{A}$ is $C_{\mathrm{AC}}\left(C_{\mathrm{AC}}>0\right)$, and the cooperation cost of enterprise $\mathrm{B}$ is $C_{\mathrm{BC}}\left(C_{\mathrm{BC}}>0\right)$. Enterprises $A$ and $B$ can achieve resource integration, joint $\mathrm{R} \& \mathrm{D}$ of new products, or further expansion of sales channels by strengthening information exchange and interaction. Thus, enterprise A can obtain cooperative income $R_{\mathrm{AC}}\left(R_{\mathrm{AC}}>0\right)$ 
and enterprise $\mathrm{B}$ can obtain cooperative income $R_{\mathrm{BC}}\left(R_{\mathrm{BC}}>0\right)$.

(2) Enterprise A adopts the embedding strategy, while enterprise $B$ chooses the nonembedding strategy, which means that there is no cooperative relationship between enterprise $\mathrm{A}$ and enterprise $\mathrm{B}$. When enterprise $\mathrm{A}$ embeds in the supply chain relationship network, the cost to be paid is $C_{\mathrm{A} 0}$, and the network income to be obtained is $R_{\mathrm{A} 0}$. When enterprise $\mathrm{B}$ chooses a nonembedding strategy, it can obtain profit $P_{\mathrm{B}}$ if it produces or sells independently, and enterprise A can obtain additional profit $L_{\mathrm{A}}\left(L_{\mathrm{A}}>0\right)$ when it cooperates with other member enterprises in the supply chain network.

(3) Enterprise A adopts nonembedding strategy, while enterprise B chooses embedding strategy, which indicates that there is no cooperative relationship between enterprise A and enterprise B. Enterprise B embeds in the supply chain network, which needs to pay $C_{\mathrm{B} 0}$ for preinvestment cost, so as to obtain network revenue $R_{\mathrm{B} 0}$. When enterprise A adopts the nonembedding strategy, it can obtain profit $P_{\mathrm{A}}$ if it produces or sells independently. Similarly, enterprise $B$ cooperates with other members of the supply chain network to obtain additional profit $L_{\mathrm{B}}\left(L_{\mathrm{B}}>0\right)$.

(4) Enterprise A adopts the nonembedding strategy, while enterprise $\mathrm{B}$ also chooses the nonembedding strategy, which means that there is no cooperative relationship between enterprise A and enterprise B. In view of this, both sides' profits from outside the supply chain network are neglected. Enterprises A and $\mathrm{B}$ choose nonembedding strategy in the supply chain network, so their preinvestment cost is 0 , and each gains profit $P_{\mathrm{A}}$ and $P_{\mathrm{B}}$ when producing or selling products independently.

To sum up, the income matrix of embedding behavior between enterprise A and enterprise B is shown in Table 1.

\subsubsection{Model Solution}

(1) According to the income matrix between enterprise $A$ and enterprise $B$ constructed above, when the probability of enterprise B choosing embedding strategy is $x$, the expected revenue of enterprise A chooses embedding strategy $U_{\mathrm{A} 1}$ :

$$
\begin{aligned}
U_{\mathrm{A} 1}= & x\left(P_{\mathrm{A}}+R_{\mathrm{A} 0}+R_{\mathrm{AC}}-C_{\mathrm{A} 0}-C_{\mathrm{AC}}\right)+(1-x)\left(P_{\mathrm{A}}\right. \\
& \left.+R_{\mathrm{A} 0}-C_{\mathrm{A} 0}+L_{\mathrm{A}}\right) .
\end{aligned}
$$

Enterprise A chooses the nonembedding strategy with the expected return of $U_{\mathrm{A} 2}$ :

$$
U_{\mathrm{A} 2}=x\left(P_{\mathrm{A}}\right)+(1-x)\left(P_{\mathrm{A}}\right) .
$$

Therefore, the average expected return of enterprise A is $U_{\mathrm{A}}$ :

$$
\begin{aligned}
U_{\mathrm{A}} \&= & \& x\left(U_{\mathrm{A} 1}\right)+(1-x) U_{\mathrm{A} 2} \\
= & x\left[x\left(P_{\mathrm{A}}+R_{\mathrm{A} 0}+R_{\mathrm{AC}}-C_{\mathrm{A} 0}-C_{\mathrm{AC}}\right)\right. \\
& \left.+(1-x)\left(P_{\mathrm{A}}+R_{\mathrm{A} 0}-C_{\mathrm{A} 0}+L_{\mathrm{A}}\right)\right] \\
& +(1-x)\left[x\left(P_{\mathrm{A}}\right)+(1-x)\left(P_{\mathrm{A}}\right)\right] .
\end{aligned}
$$

When enterprise A chooses embedding strategy and nonembedding strategy with the same expected return $\left(U_{\mathrm{A} 1}=U_{\mathrm{A} 2}\right)$, it achieves game equilibrium, that is,

$$
\begin{aligned}
& x\left(P_{\mathrm{A}}+R_{\mathrm{A} 0}+R_{\mathrm{AC}}-C_{\mathrm{A} 0}-C_{\mathrm{AC}}\right)+(1-x) \\
& \quad \cdot\left(P_{\mathrm{A}}+R_{\mathrm{A} 0}-C_{\mathrm{A} 0}+L_{\mathrm{A}}\right)=x P_{\mathrm{A}}+(1-x) P_{\mathrm{A}} .
\end{aligned}
$$

After sorting out, the following formula (1) is obtained: $\left(R_{\mathrm{AC}}-C_{\mathrm{AC}}-L_{\mathrm{A}}\right) x=C_{\mathrm{A} 0}-R_{\mathrm{A} 0}-L_{\mathrm{A}}$; that is, $x=C_{\mathrm{A} 0}-R_{\mathrm{A} 0}-L_{\mathrm{A}} / R_{\mathrm{AC}}-C_{\mathrm{AC}}-L_{\mathrm{A}}$.

(2) Similarly, when the probability of enterprise A choosing embedding strategy is $x$, the expected return of enterprise $B$ choosing embedding strategy is $U_{\mathrm{B} 1}$ :

$$
\begin{aligned}
U_{\mathrm{B} 1}= & x\left(P_{\mathrm{B}}+R_{\mathrm{B} 0}+R_{\mathrm{BC}}-C_{\mathrm{B} 0}-C_{\mathrm{BC}}\right) \\
& +(1-x)\left(P_{\mathrm{B}}+R_{\mathrm{B} 0}-C_{\mathrm{B} 0}+L_{\mathrm{B}}\right) .
\end{aligned}
$$

Enterprise B chooses the nonembedding strategy with the expected return of $U_{\mathrm{B} 2}$ :

$$
U_{\mathrm{B} 2}=x\left(P_{\mathrm{B}}\right)+(1-x)\left(P_{\mathrm{B}}\right) .
$$

Therefore, the average expected return of enterprise $B$ is $U_{\mathrm{B}}$ :

$$
\begin{aligned}
U_{\mathrm{B}}= & x\left(U_{\mathrm{B} 1}\right)+(1-x) U_{\mathrm{B} 2} \\
= & x\left[x\left(P_{\mathrm{B}}+R_{\mathrm{B} 0}+R_{\mathrm{BC}}-C_{\mathrm{B} 0}-C_{\mathrm{BC}}\right)\right. \\
& \left.+(1-x)\left(P_{\mathrm{B}}+R_{\mathrm{B} 0}-C_{\mathrm{B} 0}+L_{\mathrm{B}}\right)\right] \\
& +(1-x)\left[x\left(P_{\mathrm{B}}\right)+(1-x)\left(P_{\mathrm{B}}\right)\right] .
\end{aligned}
$$

When enterprise B chooses embedding strategy and nonembedding strategy with the same expected return $\left(U_{\mathrm{B} 1}=U_{\mathrm{B} 2}\right)$, it achieves game equilibrium, that is,

$$
\begin{aligned}
& x\left(P_{\mathrm{B}}+R_{\mathrm{B} 0}+R_{\mathrm{BC}}-C_{\mathrm{B} 0}-C_{\mathrm{BC}}\right)+(1-x) \\
& \cdot\left(P_{\mathrm{B}}+R_{\mathrm{B} 0}-C_{\mathrm{B} 0}+L_{\mathrm{B}}\right)=x P_{\mathrm{B}}+(1-x) P_{\mathrm{B}} .
\end{aligned}
$$

After sorting out, the following formula is obtained: $\left(R_{\mathrm{BC}}-C_{\mathrm{BC}}-L_{\mathrm{B}}\right) x=C_{\mathrm{B} 0}-R_{\mathrm{B} 0}-L_{\mathrm{B}}$; that is, $x=C_{\mathrm{B} 0}-R_{\mathrm{B} 0}-L_{\mathrm{B}} / R_{\mathrm{BC}}-C_{\mathrm{BC}}-L_{\mathrm{B}}$.

It can be seen that enterprise $A$ and enterprise $B$ belong to the same group and have similar industrial status. There is no difference in the probability of choosing embedding strategy and nonembedding strategy. Therefore, this paper only takes enterprise $A$ as an example to conduct a specific model analysis: 
TABLE 1: Revenue matrix of horizontal enterprise.

\begin{tabular}{lccc}
\hline \multirow{2}{*}{ Vertical enterprise embedding behavior } & Enterprise $\mathrm{B}$ & Nonembedding $(1-y)$ \\
\hline \multirow{2}{*}{ Enterprise A } & Embedding $(x)$ & $P_{\mathrm{A}}+R_{\mathrm{A} 0}+R_{\mathrm{AC}}-C_{\mathrm{A} 0}-C_{\mathrm{AC}}, P_{\mathrm{B}}+R_{\mathrm{B} 0}+R_{\mathrm{BC}}-C_{\mathrm{B} 0}-C_{\mathrm{BC}}$ & $P_{\mathrm{A}}+R_{\mathrm{A} 0}-C_{\mathrm{A} 0}+L_{\mathrm{A}}, P_{\mathrm{B}}$ \\
& Nonembedding $(1-x)$ & $P_{\mathrm{A}}, P_{\mathrm{B}}+R_{\mathrm{B} 0}-C_{\mathrm{B} 0}+L_{\mathrm{B}}$ & $P_{\mathrm{A}}, P_{\mathrm{B}}$ \\
\hline
\end{tabular}

$$
\begin{aligned}
x^{*}= & \frac{C_{\mathrm{A} 0}-R_{\mathrm{A} 0}-L_{\mathrm{A}}}{R_{\mathrm{AC}}-C_{\mathrm{AC}}-L_{\mathrm{A}}}=\frac{L_{\mathrm{A}}+\left(R_{\mathrm{A} 0}-C_{\mathrm{A} 0}\right)}{L_{\mathrm{A}}-\left(R_{\mathrm{AC}}-C_{\mathrm{AC}}\right)}=1 \\
& +\frac{\left(R_{\mathrm{AC}}-C_{\mathrm{AC}}\right)+\left(R_{\mathrm{A} 0}-C_{\mathrm{A} 0}\right)}{L_{\mathrm{A}}-\left(R_{\mathrm{AC}}-C_{\mathrm{AC}}\right)}, \\
1-x^{*}= & \frac{\left(R_{\mathrm{AC}}-C_{\mathrm{AC}}\right)+\left(R_{\mathrm{A} 0}-C_{\mathrm{A} 0}\right)}{\left(R_{\mathrm{AC}}-C_{\mathrm{AC}}\right)-L_{\mathrm{A}}}, \\
\text { or } x^{*}= & \frac{C_{\mathrm{B} 0}-R_{\mathrm{B} 0}-L_{\mathrm{B}}}{R_{\mathrm{BC}}-C_{\mathrm{BC}}-L_{\mathrm{B}}}=1+\frac{\left(R_{\mathrm{BC}}-C_{\mathrm{BC}}\right)+\left(R_{\mathrm{B} 0}-C_{\mathrm{B} 0}\right)}{L_{\mathrm{B}}-\left(R_{\mathrm{BC}}-C_{\mathrm{BC}}\right)}, \\
1-x^{*}= & \frac{\left(R_{\mathrm{BC}}-C_{\mathrm{BC}}\right)+\left(R_{\mathrm{B} 0}-C_{\mathrm{B} 0}\right)}{\left(R_{\mathrm{BC}}-C_{\mathrm{BC}}\right)-L_{\mathrm{B}}} .
\end{aligned}
$$

3.1.3. Model Analysis. In order to obtain more heterogeneous resources and information and strengthen the core competitive advantages, the enterprises should break through their inherent boundaries or frameworks and embeds in their supply chain network to seek cooperation. On this basis, they should continuously improve cooperation efficiency and maintain the stability of cooperation relations among enterprises. This paper will further analyze the interfering factors of enterprises' choice of embedding in the supply chain relationship network in order to clarify the parameters' theoretical and practical significance in the game model.

Taking enterprise $A$ as an example, the probability of enterprise choosing embedding strategy is $x *$, and we can see that the value of $x *$ is related to the values of $R_{\mathrm{AC}}, C_{\mathrm{AC}}$, $R_{\mathrm{A} 0}, \quad C_{\mathrm{A} 0}, \quad$ and $L_{\mathrm{A}}$ from $x^{*}=L_{\mathrm{A}}+\left(R_{\mathrm{A} 0}-C_{\mathrm{A} 0}\right) / L_{\mathrm{A}}-$ $\left(R_{\mathrm{AC}}-C_{\mathrm{AC}}\right)$. When other parameters are fixed, for the molecule of $x *$ value, (1) the higher the network benefit $\left(R_{\mathrm{A} 0}\right)$ of enterprise A embedding in supply chain relationship network is, the higher the possibility of choosing embedding strategy is; (2) the more assets the enterprise A invests in the supply chain relationship network are, the greater the cost of payment $\left(C_{\mathrm{A} 0}\right)$ is, the less the possibility of choosing embedding strategy is; (3) the greater the network profit $\left(R_{\mathrm{A} 0}-\mathrm{C}_{\mathrm{A} 0}\right)$ obtained by embedding in the chain network is, the greater the possibility of enterprise A choosing embedding strategy is. Similarly, when other parameters are fixed, for the denominator of the $x *$ value, (1) when enterprise $\mathrm{B}$ embeds in the supply chain relationship network, the greater the cooperative income $\left(R_{\mathrm{AC}}\right)$ obtained by cooperation between enterprise $\mathrm{A}$ and enterprise $\mathrm{B}$ is, the greater the possibility of enterprise A choosing the embedding strategy is; (2) when enterprise B embeds in the supply chain relationship network, the investment of special assets $\left(C_{\mathrm{AC}}\right)$ invested by cooperation between enterprise $\mathrm{A}$ and enterprise $\mathrm{B}$ will be greater, and the less likely the enterprise A chooses the embedding strategy; (3) when enterprise $\mathrm{B}$ embeds in the supply chain network, the greater the cooperative profit $\left(R_{\mathrm{AC}}-C_{\mathrm{AC}}\right)$ obtained by cooperation between enterprise $A$ and enterprise $B$, the greater the possibility of enterprise A choosing the embedding strategy. In addition, it is known that $\left(R_{\mathrm{AC}}-C_{\mathrm{AC}}\right)+\left(R_{\mathrm{A} 0}-C_{\mathrm{A} 0}\right) /\left(R_{\mathrm{AC}}-C_{\mathrm{AC}}\right)-L_{\mathrm{A}}>0$ from $x^{*}=1-\left(R_{\mathrm{AC}}-C_{\mathrm{AC}}\right)+\left(R_{\mathrm{A} 0}-C_{\mathrm{A} 0}\right) /\left(R_{\mathrm{AC}}-C_{\mathrm{AC}}\right)-L_{\mathrm{A}}$.

When other parameters are fixed, the greater the difference between $R_{\mathrm{AC}}-C_{\mathrm{AC}}$ and $L_{\mathrm{A}}$ is, the greater the possibility of enterprise A choosing embedding strategies is and, conversely, the greater the possibility of enterprise A choosing not embedding strategies is.

In conclusion, the probability of enterprise A choosing embedding strategy or nonembedding strategy is affected by many parameters. Among them, the greater the network profit of enterprise A is, the greater the possibility of enterprise A choosing the embedding strategy is. The greater the cooperation profit is, the greater the possibility of enterprise A choosing the embedding strategy is. The cooperation profit between enterprise $\mathrm{A}$ and enterprise $\mathrm{B}$ is obviously larger than that between enterprise A and other enterprises, and enterprise A chooses the embedding strategy and forms alliance and cooperation with enterprise $B$ is more likely with the increase of this difference.

\subsubsection{Equilibrium Stability Analysis of Horizontal} Enterprises. In view of the market symmetry of horizontal enterprises, this paper takes enterprise A as an example to unilaterally analyze the evolution of the embedding behavior of enterprise A.

It is assumed that both sides of the game are bounded rational. Since the decision-making of the enterprise involves collective decision-making, the player is aware of the ability to make mistakes and adjust the strategy, or the adjustment behavior of the enterprise is to slowly "evolve" rather than learn quickly. This paper discusses the generalized enterprise. We cannot assume that the enterprise can find the best strategy from the beginning but the random grouping of the large group members composed of the limited rational players with a lower rational level. If the rational level of the enterprise is low, it is impossible to find the best strategy from the beginning. It is impossible that all the game results are (embedded, nonembedded), usually embedded in the existing enterprise, and the enterprise is not embedded. This paper considers companies with different strategies as different types of players, but this type is not given, but changes with the players strategy. Therefore, 
xactually represents the probability of an enterprise that is agreed to be embedded in the entire enterprise group, and $1-x$ represents the probability of disagreeing with the embedded enterprise in the entire enterprise group. When the players in the enterprise group are randomly paired to perform the game, each enterprise may encounter either an embedded opponent or an unembedded opponent. So the enterprise benefits depend on its own type and the opponents type that are randomly matched. But with embedded or not embedded, the company's revenue is different. As long as the players have basic judgment, this difference will be discovered sooner or later, and companies with poor returns will find it more advantageous to change their own strategies and start to imitate another type of business. So $x$ is not fixed but changes with time according to a certain speed of change. This dynamic rate of change can be represented by a replication dynamic equation. That is, the change rate of $x$ is related to two factors. One is choosing the probability $x$ of embedding, which implies the difficulty of imitation. The second is the degree of success, that is, the difference between the expected return of the embedded enterprise and the average income of all enterprises. The formula is as follows:

$$
\frac{\mathrm{d} x}{\mathrm{~d} t}=x\left(U_{\mathrm{A} 1}-U_{\mathrm{A}}\right) .
$$

Among them, $U_{\mathrm{A} 1}$ and $U_{\mathrm{A}}$ still represent the expected return of the members and the average expected return of the members. Therefore, the enterprise A choosing the embedded dynamic differential equation of the embedded strategy is as follows:

$$
\begin{aligned}
& F(x)=\frac{\mathrm{d} x}{\mathrm{~d} t}=x\left(U_{\mathrm{A} 1}-U_{\mathrm{A}}\right)=x(1-x)\left(U_{\mathrm{A} 1}-U_{\mathrm{A} 2}\right) \\
= & x(1-x)\left[x\left(R_{\mathrm{AC}}-C_{\mathrm{AC}}-L_{\mathrm{A}}\right)+\left(R_{\mathrm{A} 0}-C_{\mathrm{A} 0}+L_{\mathrm{A}}\right)\right] .
\end{aligned}
$$

Make $\mathrm{d} x / \mathrm{d} t=0$, and get three critical values: $x=0, x=1$, and $x=R_{\mathrm{A} 0}-C_{\mathrm{A} 0}+L_{\mathrm{A}} / L_{\mathrm{A}}-R_{\mathrm{AC}+C_{\mathrm{AC}}} \cap[0,1]$.

(1) When $R_{\mathrm{AC}}-C_{\mathrm{AC}}-L_{\mathrm{A}}>0$ and $R_{\mathrm{A} 0}-C_{\mathrm{A} 0}+L_{\mathrm{A}}<0$, $\mathrm{d} x / \mathrm{d} t \geq 0 \quad$ in the interval $\quad\left(\left(C_{\mathrm{A} 0}-R_{\mathrm{A} 0^{-}}\right.\right.$ $\left.\left.L_{\mathrm{A}}\right) /\left(R_{\mathrm{AC}}-C_{\mathrm{AC}}-L_{\mathrm{A}}\right), 1\right]$. In this case, $x=1$ is the evolutionary stability point, while $x=C_{\mathrm{A} 0}-R_{\mathrm{A} 0}-$ $L_{\mathrm{A}} / R_{\mathrm{AC}}-C_{\mathrm{AC}}-L_{\mathrm{A}}$ is the unstable equilibrium point, and the embedding strategy is the evolutionary stability strategy. When $R_{\mathrm{AC}}-C_{\mathrm{AC}}-L_{\mathrm{A}}>0$ and $R_{\mathrm{A} 0}-C_{\mathrm{A} 0}+L_{\mathrm{A}}<0, \mathrm{~d} x / \mathrm{d} t \leq 0$ in the interval $\left[0, C_{\mathrm{A} 0}-R_{\mathrm{A} 0}-L_{\mathrm{A}} / R_{\mathrm{AC}}-C_{\mathrm{AC}}-L_{\mathrm{A}}\right)$. So $x=0$ is the evolutionary stability point, while $x=R_{\mathrm{A} 0}-C_{\mathrm{A} 0}$ $-C_{\mathrm{A}} / L_{\mathrm{A}}-R_{\mathrm{AC}}+C_{\mathrm{AC}}-C_{\mathrm{A}}$ is the unstable equilibrium point, and the nonembedding strategy is the evolutionary stability strategy. Thus, when the cooperative profit between enterprise $A$ and enterprise $B$ is larger than that between enterprise $A$ and other member enterprises and the network profit of enterprise $\mathrm{A}$ and the cooperative profit between enterprise $\mathrm{A}$ and other member enterprises are not enough to compensate for its embedding cost, the final result of the behavior evolution of enterprise A may be either embedding behavior or nonembedding behavior, and with the higher the $C_{\mathrm{A} 0}-$ $R_{\mathrm{A} 0}-L_{\mathrm{A}} / R_{\mathrm{AC}}-C_{\mathrm{AC}}-L_{\mathrm{A}}$ value is, the greater the possibility of enterprise A evolving into embedding behavior is.

(2) When $R_{\mathrm{AC}}-C_{\mathrm{AC}}-L_{\mathrm{A}} \leq 0$, and $R_{\mathrm{A} 0}-C_{\mathrm{A} 0}+L_{\mathrm{A}} \geq 0$, $\mathrm{d} x / \mathrm{d} t \geq 0$ in the interval $\left[0,\left(C_{\mathrm{A} 0}-R_{\mathrm{A} 0}-L_{\mathrm{A}}\right)\right.$ $\left./\left(R_{\mathrm{AC}}-C_{\mathrm{AC}}-L_{\mathrm{A}}\right)\right)$. In this case, $x=C_{\mathrm{A} 0}-R_{\mathrm{A} 0}$ $-L_{\mathrm{A}} / R_{\mathrm{AC}}-C_{\mathrm{AC}}-L_{\mathrm{A}}$ is the unstable equilibrium point. When $R_{\mathrm{AC}}-C_{\mathrm{AC}}-L_{\mathrm{A}} \leq 0$ and $R_{\mathrm{A} 0}-C_{\mathrm{A} 0}$ $+L_{\mathrm{A}} \geq 0, \quad \mathrm{~d} x / \mathrm{d} t \leq 0 \quad$ in the interval $\left(\left(C_{\mathrm{A} 0}{ }^{-}\right.\right.$ $\left.\left.R_{\mathrm{A} 0}-L_{\mathrm{A}}\right) /\left(R_{\mathrm{AC}}-C_{\mathrm{AC}}-L_{\mathrm{A}}\right), 1\right]$. In this case, $x=C_{\mathrm{A} 0}-R_{\mathrm{A} 0}-L_{\mathrm{A}} / R_{\mathrm{AC}}-C_{\mathrm{AC}}-L_{\mathrm{A}}$ is also an unstable equilibrium point.

(3) When $R_{\mathrm{AC}}-C_{\mathrm{AC}}-L_{\mathrm{A}}>0$ and $R_{\mathrm{A} 0}-C_{\mathrm{A} 0}+L_{\mathrm{A}}>0$, $\mathrm{d} x / \mathrm{d} t \geq 0$. At this point, $x=1$ is the evolutionary stability point; that is, enterprise A will eventually evolve into embedding behavior and embedding strategy is the evolutionary stability strategy. The cooperative profit between enterprise A and enterprise $B$ is larger than that between enterprise $A$ and other member enterprises. When the network profit of enterprise A and the cooperative profit between enterprise $A$ and other member enterprises are enough to compensate for the embedding cost, the final result of the behavior evolution of enterprise $\mathrm{A}$ is to adopt the embedding strategy.

(4) When $R_{\mathrm{AC}}-C_{\mathrm{AC}}-L_{\mathrm{A}} \leq 0$ and $R_{\mathrm{A} 0}-C_{\mathrm{A} 0}+L_{\mathrm{A}} \leq 0$, $\mathrm{d} x / \mathrm{d} t \leq 0$. In this case, $x=0$ is the evolutionary stability point; that is, enterprise A will eventually evolve into nonembedding behavior and nonembedding strategy is the evolutionarily stable strategy. The cooperative profit between enterprise $\mathrm{A}$ and enterprise $B$ is less than that between enterprise $A$ and other member enterprises, but when the network profit of enterprise A and the cooperative profit between enterprise A and other member enterprises are not enough to compensate for the embedded cost, the final result of the evolution of enterprise A behavior is to adopt the nonembedding behavior.

To sum up, the evolutionary results of horizontal enterprise strategic decision-making behavior may or may not be embedding strategy. On the one hand, the evolution results depend on the value of cooperative profits between enterprise $A$ and enterprise $B$ and between enterprise $A$ and other supply chain members. On the other hand, the evolution results depend on whether the sum of network profits of enterprise $\mathrm{A}$ and the profits of cooperation between enterprise $A$ and other member enterprises can compensate for the embedding cost of enterprise $A$ or not. In addition, the higher the ratio of $C_{\mathrm{A} 0}-R_{\mathrm{A} 0}-L_{\mathrm{A}} / R_{\mathrm{AC}}-C_{\mathrm{AC}}-L_{\mathrm{A}}$ is, the more likely the enterprise will evolve to adopt embedding behavior. 
3.1.5. Evolutionary Game Simulation of Horizontal Enterprise. According to the operation practice of supply chain enterprises, this paper assigns the parameters that affect the embedding behavior of supply chain enterprises taking enterprise A as an example. The cost of cooperation between enterprise A and other supply chain enterprises is higher than that between enterprise A and enterprise B. For the sake of simplicity and generality, this paper sets the network return rate of supplier enterprise $\mathrm{A}$ as $r_{\mathrm{A} 0}$, and then, the network return is $R_{\mathrm{A} 0}=\left(1+r_{\mathrm{A} 0}\right) C_{\mathrm{A} 0}$. The return rate of cooperation between enterprise $A$ and other horizontal enterprises is $r_{\mathrm{A}}$, and then, the profit of cooperation between enterprise $A$ and other horizontal enterprises is $L_{\mathrm{A}}=\left(1+r_{\mathrm{A}}\right) C_{\mathrm{A}}$. And the return rate of cooperation between enterprise $\mathrm{A}$ and enterprise $\mathrm{B}$ is $r_{\mathrm{AC}}$, then cooperation profit between enterprise $A$ and enterprise $B$ is $R_{\mathrm{AC}}=\left(1+r_{\mathrm{AC}}\right) C_{\mathrm{AC}}$. On this basis, a new replicated dynamic differential equation $F(x)$ is obtained. The initial values of the parameters are set, as shown in Table 2 :

$$
F(x)=x(1-x)\left[x\left(R_{\mathrm{AC}}-C_{\mathrm{AC}}-L_{\mathrm{A}}\right)+\left(R_{\mathrm{A} 0}-C_{\mathrm{A} 0}+L_{\mathrm{A}}\right)\right]
$$

Based on the initial values of the above parameters, the network embedding behavior strategy of supply chain enterprises is simulated by using MATLAB simulation software. As shown in Figure 2, the proportion of enterprise A choosing to embed in the supply chain relationship network will eventually converge to 1 , so the system will reach an ideal evolutionary stable state. In addition, with the increasing $x$ value, that is, more and more horizontal enterprises choose the embedding strategy in the supply chain, enterprise A tends to adjust its own strategy quickly and embedding in the supply chain relationship network.

As shown in Figure 3, the initial value of $r_{\mathrm{AC}}$ between enterprise $A$ and enterprise $B$ is changed from 0.6 to 0.4 and 0.8 , respectively, and different simulation results are obtained. When the cooperative rate of return between enterprise $\mathrm{A}$ and enterprise $\mathrm{B}$ decreases, that is, $r_{\mathrm{AC}}=0.4$, the proportion of enterprise A choosing the embedding strategy decreases, and the sensitivity to external environment change also decreases. When the cooperative rate of return between enterprise $\mathrm{A}$ and enterprise $\mathrm{B}$ increases, that is, $r_{\mathrm{AC}}=0.8$, the proportion of enterprise A choosing the embedding strategy increases, and the sensitivity to external environmental changes has also been improved. Thus, the higher the cooperative rate of return between supply chain enterprise $A$ and enterprise $B$ is, the larger the proportion of enterprise A choosing the embedding strategy is. That is, when supply chain enterprise A perceives the embedding in a supply chain relationship network, the more profitable it is to cooperate with enterprise $\mathrm{B}$, the more likely it is to choose the embedding strategy.

In addition, in order to further explore the dynamic trend of horizontal enterprises' embedding behaviors in supply chain, this paper sets $a=R_{\mathrm{AC}}-C_{\mathrm{AC}}-L_{\mathrm{A}}$ and $b=R_{\mathrm{A} 0}-C_{\mathrm{A} 0}+L_{\mathrm{A}}$, and $C_{1}$ and $C_{2}$ are the initial values of replicating dynamic differential equations, respectively. The initial values of parameters are set, as shown in Table 3.
As shown in Figure 4, picture coding (2), (3), (5), (8), and (10) show that although the proportion of enterprise $A$ choosing to embed in the supply chain relationship network fluctuates near the value 1 , it will converge to 1 with the change of time $t$; thus, the system reaches an ideal evolutionary stable state; that is, $x=1$ is the evolutionary stable point, and the embedding strategy is the evolutionary stable strategy.

However, the picture coding (1), (4), (6), (7), and (9) shows that although the proportion of enterprise A choosing to embed in the supply chain relationship network oscillates near the value 0 , it will eventually converge to 0 with the change in time $t$; thus, the system achieves an ideal evolutionary stable state; that is, $x=0$ is the evolutionary stable point, and the nonembedding strategy is the evolutionary stable strategy. Thus, although the initial values and parameters of the equation are different, the system will eventually stabilize at the equilibrium point of $x=0$ or $x=1$ with the time $t$ changing periodically.

\subsection{Evolutionary Game Analysis of Vertical Enterprises.} The vertical cooperative behavior of enterprises in the supply chain network is mainly manifested in the vertical cooperative relationship or behavior between supplier and manufacturer and manufacturer and retailer. Through the specialized division of labor among enterprises, the production efficiency of enterprises and the overall operation ability of the supply chain can be improved.

3.2.1. Model Building. Assuming that an enterprise has the independent decision-making power of embedding in a supply chain relationship network, the relationship among the main bodies is a vertical cooperative relationship, and its strategy space is (embedding, nonembedding). Enterprises choose embedding strategy, which means that enterprises choose to cooperate with upstream and downstream members of the supply chain network to form an alliance relationship. On the one hand, enterprises embedding in the supply chain network can obtain heterogeneous resources and information needed for the enterprises development. These resources and information can be further transformed into social capital or relational capital. This paper names them as network gains. On the other hand, cooperation between enterprises and upstream and downstream member enterprises can reduce information asymmetry and transaction costs and then improve cooperation efficiency. Assuming that enterprise $S$ is the supplier, enterprise $M$ is the manufacturer, and enterprise $S$ and enterprise $M$ adopt the embedding strategy, indicating that there is a cooperative relationship between enterprise $S$ and enterprise $M$, which can generate certain cooperation benefits. If neither enterprise S nor enterprise $M$ decides to embeds in the supply chain network, the profits from independent production or sales are $P_{\mathrm{S}}\left(P_{\mathrm{S}}>0\right)$ and $P_{\mathrm{M}}\left(P_{\mathrm{M}}>0\right)$. In addition, in the vertical enterprise group, the probability of supplier group adopting embedding strategy is assumed to be $x(0<x<1)$, the probability of nonembedding strategy is $(1-x)$, the probability of manufacturer group adopting embedding 
TABLE 2: Initial values of parameters and implications.

\begin{tabular}{lcc}
\hline Parameter name & Initial value & Parameter implication \\
\hline$r_{\mathrm{A} 0}$ & 0.1 & Network return rate of enterprise A \\
$r_{\mathrm{A}}$ & 0.25 & Cooperation rate of return between enterprise A and other enterprises \\
$r_{\mathrm{AC}}$ & 0.6 & Cooperation rate of return between enterprise A and enterprise B \\
$C_{\mathrm{A} 0}$ & 1 & Special assets investment cost of enterprise A \\
$\mathrm{C}_{\mathrm{AC}}$ & 2 & Cooperation cost between enterprise A and enterprise B \\
$C_{\mathrm{A}}$ & 4 & Cooperation cost between enterprise A and other enterprises \\
\hline
\end{tabular}

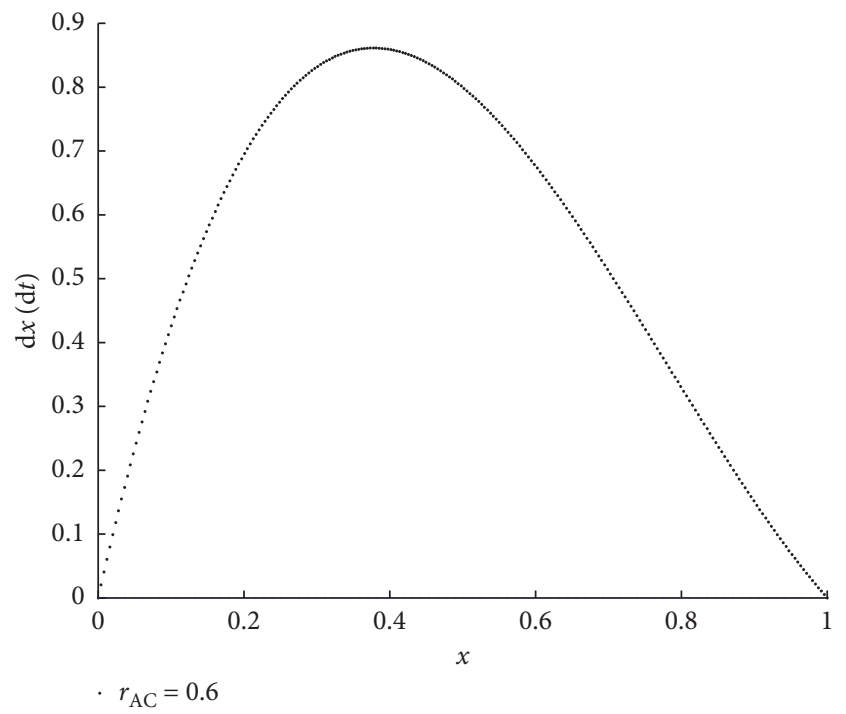

FIgURE 2: Initial simulation experiments.

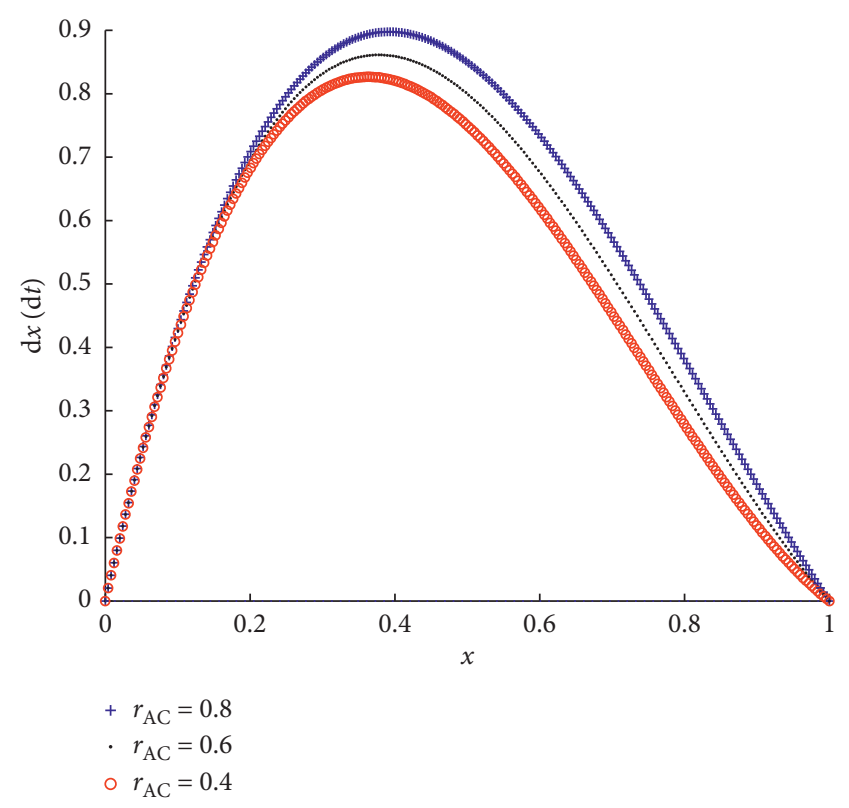

Figure 3: Simulation test results.

strategy is $y(0<y<1)$, and the probability of nonembedding strategy is $(1-y)$. The total income of an enterprise is the sum of the income from independent production or sales and the income from cooperation.
TABLE 3: Initial setting of parameters for horizontal enterprises.

\begin{tabular}{lcccc}
\hline Picture coding & $a$ & $b$ & $C_{1}$ & $C_{2}$ \\
\hline (1) & -0.660 & 0.050 & 0.090 & 0.091 \\
(2) & -0.060 & 0.050 & 0.010 & 0.011 \\
(3) & 200 & 300 & 0.01 & 0.011 \\
(4) & -200 & -300 & 0.01 & 0.011 \\
(5) & -6 & 5 & 0.01 & 0.011 \\
(6) & 6 & -5 & 0.01 & 0.011 \\
(7) & 200 & -3 & 0.01 & 0.011 \\
(8) & 2 & 1 & 0.01 & 0.011 \\
(9) & -200 & -100 & 0.01 & 0.011 \\
(10 & -200 & 200 & 0.01 & 0.011 \\
\hline
\end{tabular}

(1) Enterprise S adopts the embedding strategy, and enterprise $M$ also adopts the embedding strategy, which means that there is a cooperative relationship between enterprise $S$ and enterprise $M$. When enterprises $\mathrm{S}$ and $\mathrm{M}$ choose to embed in supply chain network, they need to bear certain social responsibility and pay a certain cost; that is, the investment cost of special assets is $C_{\mathrm{S} 0}\left(C_{\mathrm{S} 0}>0\right)$ and $C_{\mathrm{M} 0}\left(C_{\mathrm{M} 0}>0\right)$, so as to obtain social capital; that is, network income is $R_{\mathrm{S} 0}\left(R_{\mathrm{S} 0}>0\right)$ and $R_{\mathrm{M} 0}\left(R_{\mathrm{M} 0}>0\right)$. In addition, when enterprise $S$ and enterprise $M$ form a contractual relationship, they need to invest a certain time cost and transaction cost; that is, the cooperation cost of enterprise $S$ is $C_{S C}\left(C_{S C}>0\right)$, and the cooperation cost of enterprise $\mathrm{M}$ is $\mathrm{C}_{\mathrm{MC}}\left(C_{\mathrm{MC}}>0\right)$. Enterprise $S$ and enterprise $M$ can effectively improve the overall specialization level and cooperation efficiency of supply chain by strengthening information interaction and cooperation. Therefore, enterprise $\mathrm{S}$ can further obtain cooperative revenue $R_{\mathrm{SC}}$ $\left(R_{\mathrm{SC}}>0\right)$ and enterprise $\mathrm{M}$ can obtain cooperative revenue $R_{\mathrm{MC}}\left(R_{\mathrm{MC}}>0\right)$.

(2) Enterprise $S$ adopts an embedding strategy, while enterprise $M$ chooses nonembedding strategy, which means that there is no cooperative relationship between enterprise $S$ and enterprise $M$. When enterprise $S$ embeds in the supply chain network, the cost to be paid is $C_{\mathrm{S} 0}$, and the social capital to be obtained is $R_{\mathrm{S} 0}$. When enterprise $\mathrm{M}$ chooses the nonembedding strategy, the additional profit obtained by cooperation between enterprise $S$ and other manufacturers in the supply chain network is $L_{S}\left(L_{S}>0\right)$, while enterprise $M$ can obtain profit $P_{\mathrm{M}}$ when it produces or sells independently. 


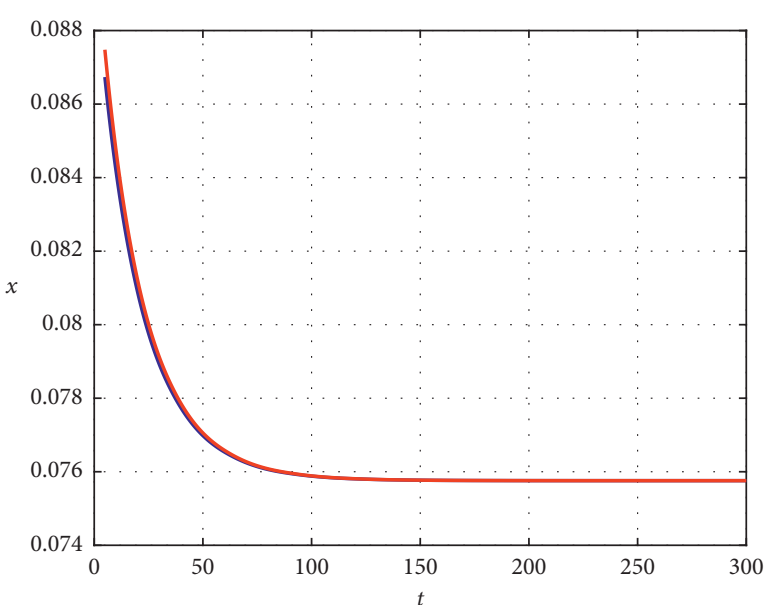

$\begin{aligned} c 1 & =0.09\end{aligned}$

(a)

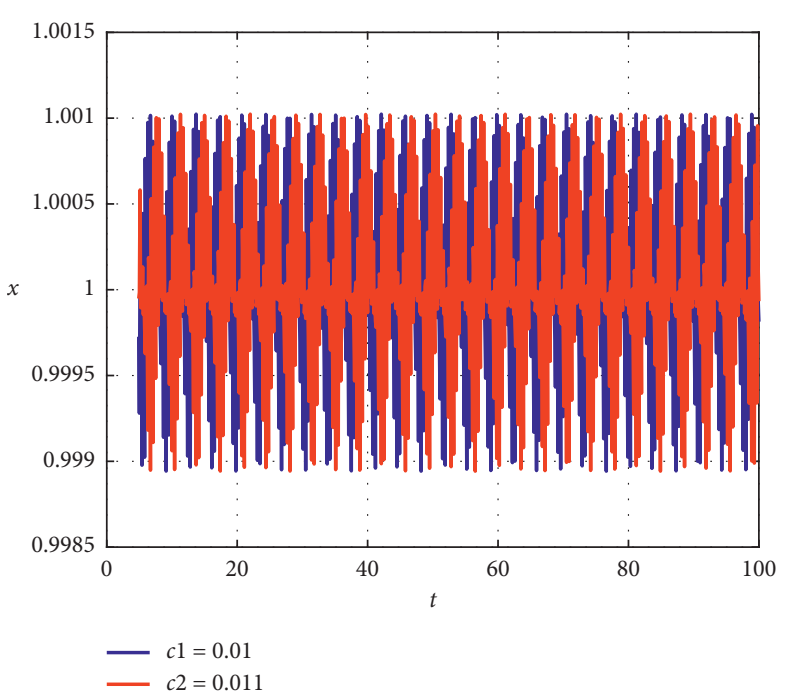

(c)

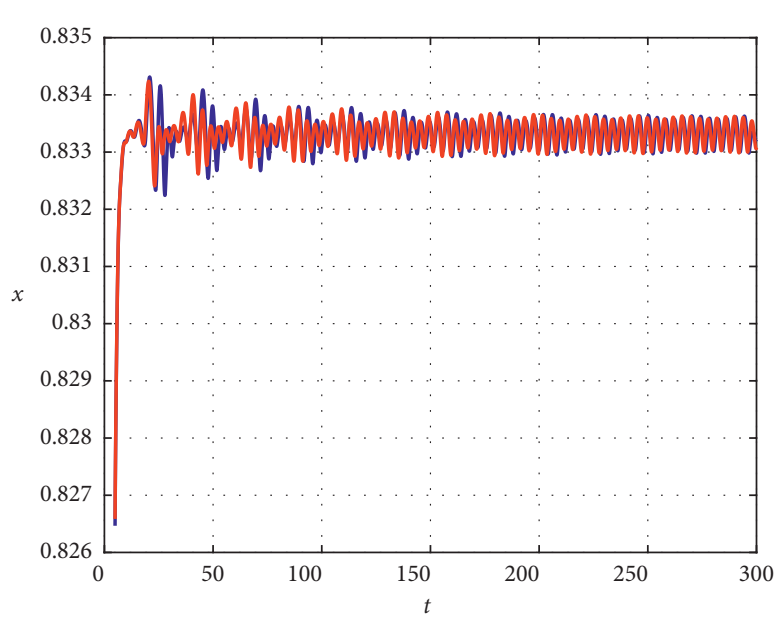

$\begin{aligned}-c 1 & =0.01 \\ -c 2 & =0.011\end{aligned}$

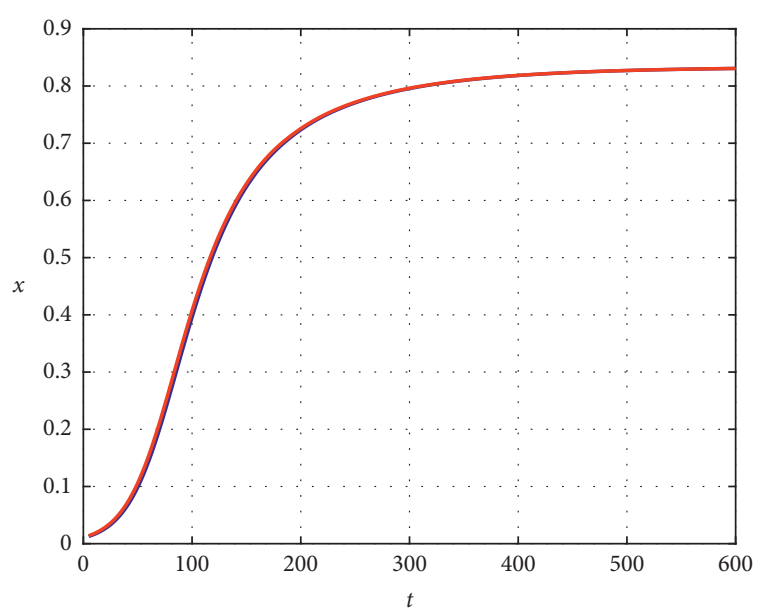

$\begin{array}{cl}-c 1 & =0.01\end{array}$

(b)

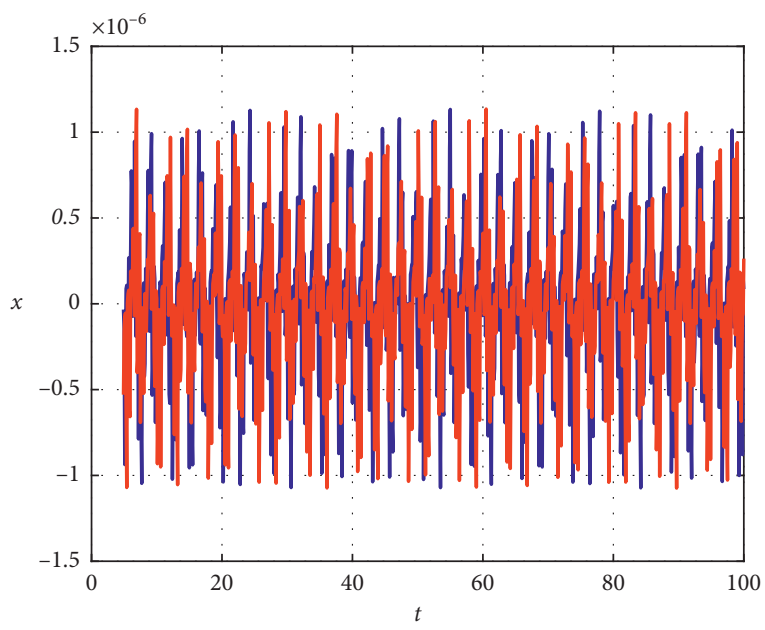

$\begin{aligned}-c 1 & =0.01 \\ - & =0.011\end{aligned}$

(d)

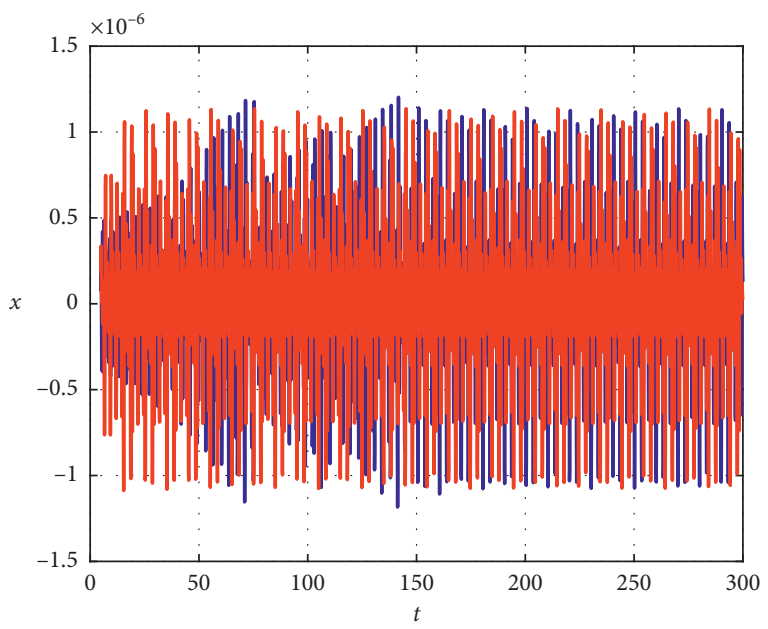

$\begin{aligned}-c 1 & =0.01 \\ -c 2 & =0.011\end{aligned}$

(e)

Figure 4: Continued. 

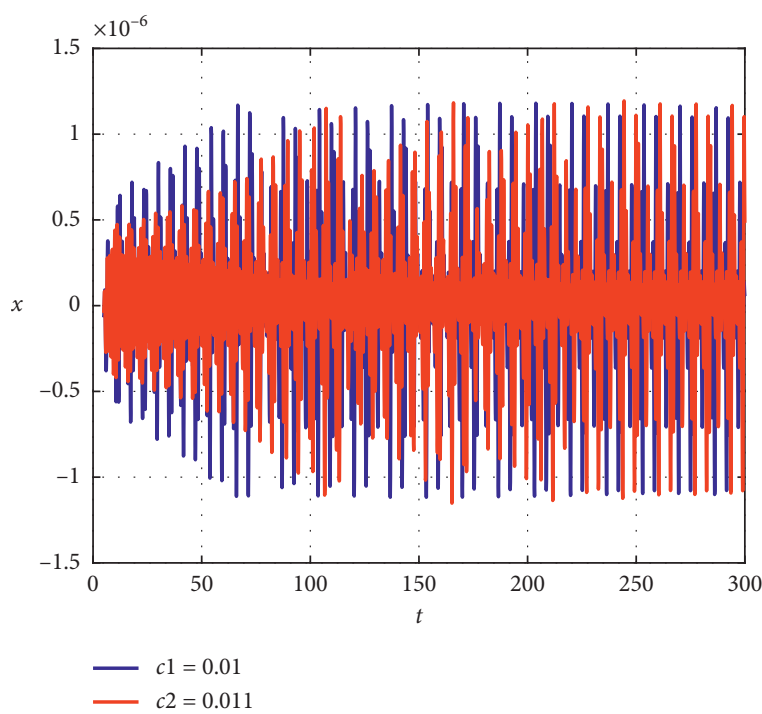

(g)

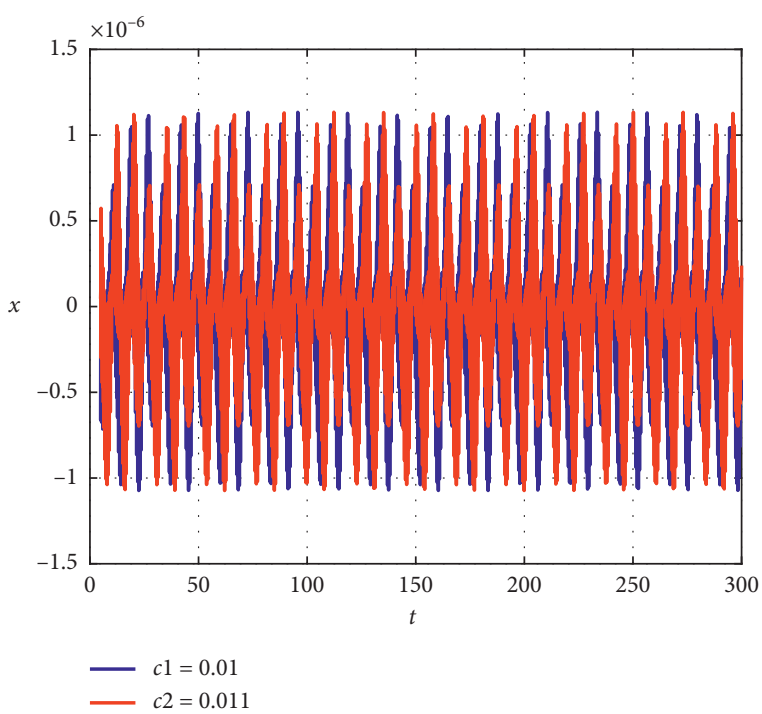

(i)

FIGURE 4: Simulated graph of horizontal enterprises: (a) (1);

(3) Enterprise $S$ adopts a nonembedding strategy, while enterprise $M$ chooses embedding strategy, which indicates that there is no cooperative relationship between enterprise $S$ and enterprise $M$. Enterprise $M$ embeds in the supply chain network, which needs to pay $C_{\mathrm{M} 0}$ for the preinvestment cost, so as to obtain $R_{\mathrm{M} 0}$ network revenue. When enterprise $S$ adopts the nonembedding strategy, the additional profit obtained by enterprise $M$ cooperating with other suppliers in the supply chain network is $L_{\mathrm{M}}\left(L_{\mathrm{M}}>0\right)$, while enterprise $\mathrm{S}$ can obtain the profit $P_{\mathrm{S}}$ when it produces or sells independently.

(4) Enterprise S adopts a nonembedding strategy, and enterprise $\mathrm{M}$ also chooses a nonembedding strategy, which means that there is no cooperative relationship between enterprise $S$ and enterprise $M$. Both

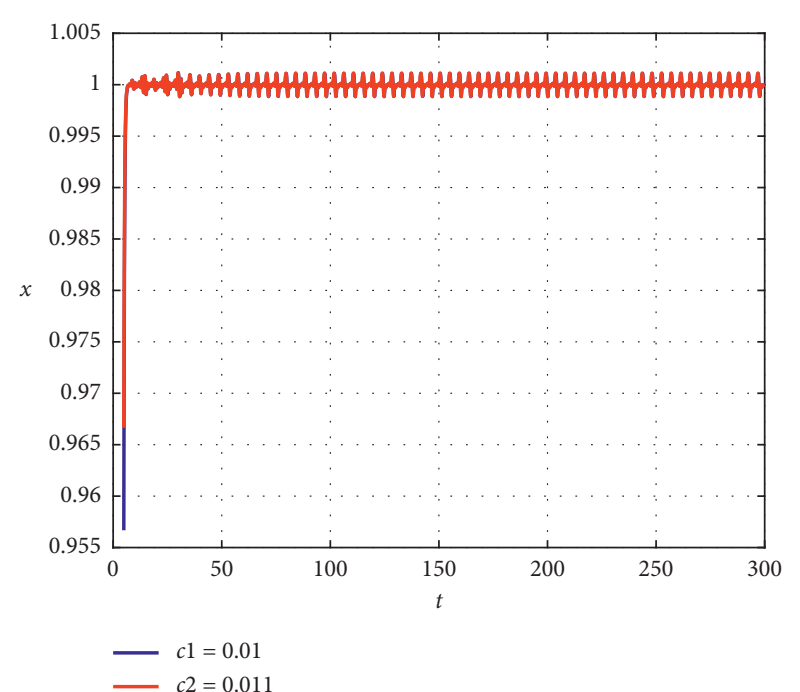

(h)

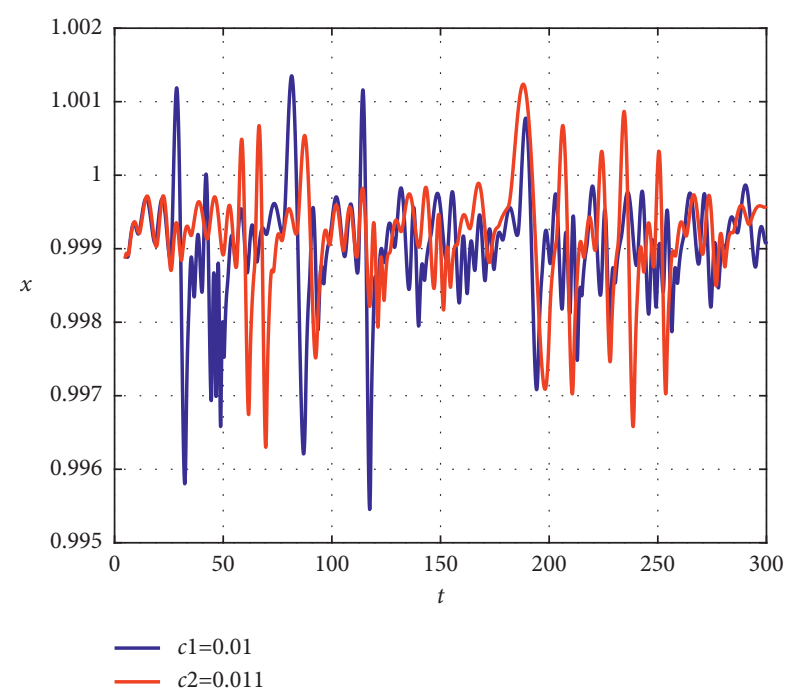

(j)

(b) (2); (c) (3); (d) (4); (e) (5); (f) (6); (g) (7); (h) (8); (i) (9); (j) (10)

enterprise $\mathrm{S}$ and enterprise $\mathrm{M}$ choose not to embed in the supply chain relationship network, so their preinvestment cost is 0 . In view of this, the profits of enterprise $S$ and enterprise $M$ from the outside of supply chain network are neglected, so they obtain their own profits $P_{\mathrm{S}}$ and $P_{\mathrm{M}}$ when they produce or sell independently.

To sum up, the income matrix of the embedding behavior between enterprise $S$ and enterprise $M$ is shown in Table 4.

\subsubsection{Model Solution}

(1) According to the revenue matrix between enterprise $S$ and enterprise $M$ constructed above, when the probability of enterprise $\mathrm{M}$ choosing embedding 
TABLE 4: Revenue matrix of vertical enterprises.

\begin{tabular}{|c|c|c|c|}
\hline \multirow{2}{*}{\multicolumn{2}{|c|}{ Vertical enterprise embedding behavior }} & \multicolumn{2}{|l|}{ Enterprise $\mathrm{M}$} \\
\hline & & Embedding $(y)$ & Nonembedding $(1-y)$ \\
\hline Enterprise $\mathrm{S}$ & $\begin{array}{c}\text { Embedding }(x) \\
\text { Nonembedding }(1-x)\end{array}$ & $\begin{array}{c}P_{\mathrm{S}}+R_{\mathrm{S} 0}+R_{\mathrm{SC}}-C_{\mathrm{S} 0}-C_{\mathrm{SC}}, P_{\mathrm{M}}+R_{\mathrm{M} 0}+R_{\mathrm{MC}}-C_{\mathrm{M} 0}-C_{\mathrm{MC}} \\
P_{\mathrm{S}}, P_{\mathrm{M}}+R_{\mathrm{M} 0}-C_{\mathrm{M} 0}+L_{\mathrm{M}}\end{array}$ & $\begin{array}{c}P_{\mathrm{S}}+R_{\mathrm{S} 0}-C_{\mathrm{S} 0}+L_{\mathrm{S}}, P_{\mathrm{M}} \\
P_{\mathrm{S}}, P_{\mathrm{M}}\end{array}$ \\
\hline
\end{tabular}

strategy is $y$, the expected revenue of enterprise $\mathrm{S}$ choosing embedding strategy is $U_{\mathrm{S} 1}$ :

$$
\begin{aligned}
U_{\mathrm{S} 1}= & y\left(P_{\mathrm{S}}+R_{\mathrm{S} 0}+R_{\mathrm{SC}}-C_{\mathrm{S} 0}-C_{\mathrm{SC}}\right) \\
& +(1-y)\left(P_{\mathrm{S}}+R_{\mathrm{S} 0}-C_{\mathrm{S} 0}+L_{\mathrm{S}}\right) .
\end{aligned}
$$

The expected return of enterprise $S$ choosing nonembedding strategy is $U_{\mathrm{S} 2}$ :

$$
U_{\mathrm{S} 2}=y\left(P_{\mathrm{S}}\right)+(1-y) P_{\mathrm{S}} .
$$

Therefore, the average expected return of enterprise $S$ is $U_{S}$ :

$$
\begin{aligned}
U_{\mathrm{S}}= & x U_{\mathrm{S} 1}+(1-x) U_{\mathrm{S} 2} \\
= & x\left[y\left(P_{\mathrm{S}}+R_{\mathrm{S} 0}+R_{\mathrm{SC}}-C_{\mathrm{S} 0}-C_{\mathrm{S} C}\right)+(1-y)\right. \\
& \left.\cdot\left(P_{\mathrm{S}}+R_{\mathrm{S} 0}-C_{\mathrm{S} 0}+L_{\mathrm{S}}\right)\right]+(1-x) \\
& \cdot\left[y\left(P_{\mathrm{S}}\right)+(1-y)\left(P_{\mathrm{S}}\right)\right] .
\end{aligned}
$$

When the expected return of $\mathrm{S}$ choosing embedding strategy and nonembedding strategy is equal $\left(U_{\mathrm{S} 1}=U_{\mathrm{S} 2}\right)$, the game equilibrium is realized, that is,

$$
\begin{gathered}
y\left(P_{\mathrm{S}}+R_{\mathrm{S} 0}+R_{\mathrm{SC}}-C_{\mathrm{S} 0}-C_{\mathrm{SC}}\right)+(1-y)\left(P_{\mathrm{S}}\right. \\
\left.\quad+R_{\mathrm{S} 0}-C_{\mathrm{S} 0}+L_{\mathrm{S}}\right)=y\left(P_{\mathrm{S}}\right)+(1-y)\left(P_{\mathrm{S}}\right) .
\end{gathered}
$$

After sorting out, the following formulas are obtained:

$$
\begin{gathered}
\left(R_{\mathrm{SC}}-C_{\mathrm{SC}}-L_{\mathrm{S}}\right) y=C_{\mathrm{S} 0}-R_{\mathrm{S} 0}, \\
y^{*}=\frac{C_{\mathrm{S} 0}-R_{\mathrm{S} 0}}{R_{\mathrm{SC}}-C_{\mathrm{SC}}-L_{\mathrm{S}}}=\frac{R_{\mathrm{S} 0}-C_{\mathrm{S} 0}}{L_{\mathrm{S}}-\left(R_{\mathrm{SC}}-C_{\mathrm{SC}}\right)} \\
=1-\frac{\left(R_{\mathrm{SC}}-C_{\mathrm{SC}}\right)-\left(C_{\mathrm{S} 0}-R_{\mathrm{S} 0}\right)-L_{\mathrm{S}}}{L_{\mathrm{S}}-\left(R_{\mathrm{SC}}-C_{\mathrm{SC}}\right)}, \\
1-y^{*}=\frac{\left(R_{\mathrm{SC}}-C_{\mathrm{SC}}\right)-\left(C_{\mathrm{S} 0}-R_{\mathrm{S} 0}\right)-L_{\mathrm{S}}}{L_{\mathrm{S}}-\left(R_{\mathrm{SC}}-C_{\mathrm{SC}}\right)} .
\end{gathered}
$$

(2) Similarly, according to the revenue matrix between enterprise $S$ and enterprise $M$, when the probability of enterprise $\mathrm{S}$ choosing embedding strategy is $x$, the expected revenue of enterprise $\mathrm{M}$ choosing embedding strategy is $U_{\mathrm{M} 1}$ :

$$
\begin{aligned}
U_{\mathrm{M} 1}= & x\left(P_{\mathrm{M}}+R_{\mathrm{M} 0}+R_{\mathrm{MC}}-C_{\mathrm{M} 0}-C_{\mathrm{MC}}\right) \\
& +(1-x)\left(P_{\mathrm{M}}+R_{\mathrm{M} 0}-C_{\mathrm{M} 0}+L_{\mathrm{M}}\right) .
\end{aligned}
$$

Enterprise $M$ chooses the nonembedding strategy with the expected return of $U_{\mathrm{M} 2}$ :

$$
U_{\mathrm{M} 2}=x\left(P_{\mathrm{M}}\right)+(1-x)\left(P_{\mathrm{M}}\right) \text {. }
$$

Therefore, the average expected return of enterprise $M$ is $U_{\mathrm{M}}$ :

$$
\begin{aligned}
U_{M}= & y U_{M 1}+(1-y) U_{\mathrm{M} 2}=y\left[x \left(P_{\mathrm{M}}+R_{\mathrm{M} 0}+R_{\mathrm{MC}}-C_{\mathrm{M} 0}\right.\right. \\
& \left.\left.-C_{\mathrm{MC}}\right)+(1-x)\left(P_{\mathrm{M}}+R_{\mathrm{M} 0}-C_{\mathrm{M} 0}+L_{\mathrm{M}}\right)\right] \\
& +(1-y)\left[x\left(P_{\mathrm{M}}\right)+(1-x)\left(P_{\mathrm{M}}\right)\right] .
\end{aligned}
$$

When enterprise $M$ chooses embedding strategy and nonembedding strategy with the same expected return $\left(U_{\mathrm{M} 1}=U_{\mathrm{M} 2}\right)$, it achieves game equilibrium, that is,

$$
\begin{gathered}
x\left(P_{\mathrm{M}}+R_{\mathrm{M} 0}+R_{\mathrm{MC}}-C_{\mathrm{M} 0}-C_{\mathrm{MC}}\right)+(1-x)\left(P_{\mathrm{M}}+R_{\mathrm{M} 0}\right. \\
\left.-C_{\mathrm{M} 0}+L_{\mathrm{M}}\right)=x\left(P_{\mathrm{M}}\right)+(1-x)\left(P_{\mathrm{M}}\right) .
\end{gathered}
$$

After sorting out, the formula (2) is obtained: $\left(R_{\mathrm{MC}}-C_{\mathrm{MC}}-L_{\mathrm{M}}\right) x=C_{\mathrm{M} 0}-R_{\mathrm{M} 0}$ :

$$
\begin{aligned}
x^{*} & =\frac{C_{\mathrm{M} 0}-R_{\mathrm{M} 0}}{R_{\mathrm{MC}}-C_{\mathrm{MC}}-L_{\mathrm{M}}}=\frac{R_{\mathrm{M} 0}-C_{\mathrm{M} 0}}{L_{\mathrm{M}}-\left(R_{\mathrm{MC}}-C_{\mathrm{MC}}\right)} \\
& =1-\frac{\left(R_{\mathrm{MC}}-C_{\mathrm{MC}}\right)-\left(C_{\mathrm{M} 0}-R_{\mathrm{M} 0}\right)-L_{\mathrm{M}}}{L_{\mathrm{M}}-\left(R_{\mathrm{MC}}-C_{\mathrm{MC}}\right)},
\end{aligned}
$$

$1-x^{*}=\frac{\left(R_{\mathrm{MC}}-C_{\mathrm{MC}}\right)-\left(C_{\mathrm{M} 0}-R_{\mathrm{M} 0}\right)-L_{\mathrm{M}}}{L_{\mathrm{M}}-\left(R_{\mathrm{MC}}-C_{\mathrm{MC}}\right)}$.

3.2.3. Model Analysis. In order to further strengthen their core competitive advantages, enterprises should embed in their supply chain network and seek to build a cooperative relationship with upstream and downstream enterprises. On this basis, they should continuously improve the level of specialization and cooperation efficiency and maintain the stability of cooperative relationship between enterprises. This paper will further analyze the influencing factors of upstream and downstream member enterprises' choice of embedding in the supply chain network in order to clarify the theoretical and practical significance of the parameters of the game model.

(1) The probability of enterprise $S$ choosing embedding strategy is $x *$, it is seen that $x *$ is related to the values of $R_{\mathrm{MC}}, C_{\mathrm{MC}}, R_{\mathrm{M} 0}, C_{\mathrm{M} 0}$, and $L_{\mathrm{M}}$ from $x^{*}=R_{\mathrm{M} 0}-C_{\mathrm{M} 0} / L_{\mathrm{M}}-\left(R_{\mathrm{MC}}-C_{\mathrm{MC}}\right)$. When other parameters are fixed, for the molecule of $x *$ value, (1) 
the greater the network revenue $\left(R_{\mathrm{M} 0}\right)$ of enterprise $M$ embedding in the supply chain relationship network is, the greater the possibility of enterprise $S$ choosing to embedding is; (2) the more assets the enterprise $M$ invests in the supply chain relationship network, the greater the cost of payment $\left(C_{\mathrm{M} 0}\right)$ is, the smaller the possibility of enterprise $S$ choosing to embedding is; (3) the greater the network profit $\left(R_{\mathrm{M} 0^{-}} C_{\mathrm{M} 0}\right)$ of the enterprise $\mathrm{M}$ choosing to embedding is, the greater the possibility of enterprise $S$ choosing embedding strategy is. Similarly, when other parameters are fixed, for the denominator of $x *$ value, (1) when enterprise S embeds in the supply chain network, the greater the cooperative benefit $\left(R_{\mathrm{MC}}\right)$ of cooperation between enterprise $\mathrm{M}$ and enterprise $S$ is, the greater the possibility of enterprise $\mathrm{S}$ choosing the embedding strategy is; (2) when enterprise $S$ embeds in the supply chain network, the investment of special assets invested by enterprise $M$ and enterprise $S$ in cooperation is greater, the greater the cost $\left(C_{\mathrm{MC}}\right)$ is, and the less likely the enterprise $S$ chooses the embedding strategy; (3) when the enterprise $S$ embeds in the supply chain network, the greater the cooperative profit $\left(R_{\mathrm{MC}} C_{\mathrm{MC}}\right)$ obtained by the cooperation between enterprise $M$ and enterprise $S$ is, the more likely the enterprise $S$ chooses the embedding strategy; (4) when enterprise $S$ does not embed in the supply chain network, the larger the cooperative profit $\left(L_{\mathrm{M}}\right)$ is, the smaller the possibility of S choosing embedding strategy is; (5) the smaller the difference between cooperative profit $\left(L_{\mathrm{M}}\right)$ between enterprise $\mathrm{M}$ and other member enterprises and cooperative profit $\left(R_{\mathrm{MC}}{ }^{-} C_{\mathrm{MC}}\right)$ between enterprise $M$ and enterprise $S$ is, the greater the possibility of $S$ choosing embedding strategy is, and conversely, the greater the possibility of $S$ choosing nonembedding strategy is.

In summary, the probability of enterprise $S$ choosing embedding strategy and nonembedding strategy is affected by many parameters of enterprise M. Among them, the greater the network profit of enterprise $M$ embedding in the supply chain relationship network is, the greater the possibility of enterprise $S$ choosing the embedding strategy is. The greater the cooperative profit of enterprise $M$ and enterprise $S$ is, the greater the possibility of enterprise $\mathrm{S}$ choosing the embedding strategy is. When the cooperative profit between enterprise $\mathrm{M}$ and other suppliers is obviously larger than that between enterprise $M$ and enterprise $S$, the enterprise $S$ chooses the embedding strategy with the increase in the gap and forms alliance and cooperating with $\mathrm{M}$.

(2) The probability of enterprise $M$ choosing embedding strategy is $y *$, and it is known that it is determined by the values of $R_{\mathrm{SC}}, C_{\mathrm{SC}}, R_{\mathrm{S} 0}, C_{\mathrm{S} 0}$, and $L_{\mathrm{S}}$ from $y^{*}=R_{\mathrm{S} 0}-C_{\mathrm{S} 0} / L_{\mathrm{S}}-\left(R_{\mathrm{SC}}-C_{\mathrm{SC}}\right)$. When other parameters are fixed, for the molecule of the y* value, $(1)$ the greater the network revenue $\left(R_{\mathrm{S} 0}\right)$ of enterprise $S$ embedding in supply chain network is, the greater the possibility of enterprise $M$ choosing to embedding is; (2) the more assets invested in supply chain relationship network invests the enterprise $S$, the greater the cost of payment $\left(C_{\mathrm{S} 0}\right)$ is, and the smaller the possibility of enterprise $M$ choosing to embedding is; and (3) the larger the network profit $\left(R_{\mathrm{S} 0}-C_{\mathrm{S} 0}\right)$ is, the greater the possibility of enterprise $M$ choosing embedding strategy is. Similarly, when other parameters are fixed, for the denominator of $y *$ value, (1) when enterprise $M$ embeds in the supply chain network, the greater the cooperative benefit $\left(R_{\mathrm{SC}}\right)$ obtained by cooperation between enterprise $S$ and enterprise $\mathrm{M}$ is, the greater the possibility of enterprise $M$ choosing the embedding strategy is; (2) when enterprise $\mathrm{M}$ embeds in the supply chain network, the greater the cost $\left(C_{\mathrm{SC}}\right)$ of special assets invested by cooperation between enterprise $S$ and enterprise $\mathrm{M}$ is, the less likely the enterprise $\mathrm{M}$ chooses the embedding strategy; (3) when the enterprise $M$ embeds in the supply chain network, the greater the cooperative profit $\left(R_{\mathrm{SC}} C_{\mathrm{SC}}\right)$ obtained by the cooperation between enterprise $S$ and enterprise $M$ is, the more likely the enterprise $\mathrm{M}$ chooses the embedding strategy; (4) when enterprise $M$ does not embed in the supply chain network, the larger the cooperative profit $\left(L_{S}\right)$ is, the smaller the possibility of enterprise $M$ choosing the embedding strategy is; (5) the smaller the difference $\left(L_{\mathrm{S}}-R_{\mathrm{SC}}+\mathrm{C}_{\mathrm{SC}}\right)$ between cooperative profit $\left(L_{\mathrm{S}}\right)$ and cooperative profit $\left(R_{\mathrm{SC}}-C_{\mathrm{SC}}\right)$ is, the greater the possibility of enterprise $M$ choosing the embedding strategy is, and conversely, the greater the possibility of enterprise $M$ choosing the nonembedding strategy is.

In summary, the probability of enterprise $\mathrm{M}$ choosing embedding strategy and nonembedding strategy is affected by many parameters of enterprise S. Among them, the greater the network profit of enterprise $S$ embedding in the supply chain network is, the greater the possibility of enterprise $\mathrm{M}$ choosing the embedding strategy is. The greater the cooperative profit of enterprise $S$ and enterprise $M$ is, the greater the possibility of enterprise $\mathrm{M}$ choosing the embedding strategy is. When the cooperative profit of enterprise $S$ and other manufacturer enterprises is obviously larger than that of enterprise $S$ and enterprise $M$, the possibility of $\mathrm{M}$ choosing embedding strategy and forming alliance and cooperating with $S$ with the increase in this gap becomes greater.

3.2.4. Equilibrium Stability Analysis of Enterprises. This paper analyzes the evolution of embedding behaviors of enterprise $S$ and enterprise $M$, respectively.

The replication dynamic differential equation of enterprise $\mathrm{S}$ choosing embedding strategy is 


$$
\begin{aligned}
F(x) & =\frac{\mathrm{d} x}{\mathrm{~d} t}=x\left(U_{\mathrm{S} 1}-U_{\mathrm{S}}\right)=x(1-x)\left(U_{\mathrm{S} 1}-U_{\mathrm{S} 2}\right) \\
& =x(1-x)\left[y\left(R_{\mathrm{SC}}-C_{\mathrm{S} C}-L_{\mathrm{S}}\right)+\left(R_{\mathrm{S} 0}-C_{\mathrm{S} 0}+L_{\mathrm{S}}\right)\right] .
\end{aligned}
$$

Set $\mathrm{d} x / \mathrm{d} t=0$, and get three critical values: $x=0, x=1$, and $y_{0}=R_{\mathrm{S} 0}-C_{\mathrm{S} 0}+L_{\mathrm{S}} / L_{\mathrm{S}}-R_{\mathrm{SC}+C_{\mathrm{SC}}}$.

Similarly, the replication dynamic differential equation of enterprise $\mathrm{M}$ choosing embedding strategy is

$$
\begin{aligned}
F(y) & =\frac{\mathrm{d} y}{\mathrm{~d} t}=y\left(U_{\mathrm{M} 1}-U_{\mathrm{M}}\right)=y(1-y)\left(U_{\mathrm{M} 1}-U_{\mathrm{M} 2}\right) \\
& =y(1-y)\left[x\left(R_{\mathrm{MC}}-C_{\mathrm{MC}}-L_{\mathrm{M}}\right)+\left(R_{\mathrm{M} 0}-C_{\mathrm{M} 0}+L_{\mathrm{M}}\right)\right] .
\end{aligned}
$$

Set $\mathrm{d} y / \mathrm{d} t=0$, and get three critical values: $y=0, y=1$, and $x_{0}=R_{\mathrm{M} 0}-C_{\mathrm{M} 0}+L_{\mathrm{M}} / L_{\mathrm{M}}-R_{\mathrm{MC}+C_{\mathrm{MC}}}$.

In summary, this paper gets five equilibrium points such as $A(0,0), B(1,0), C(0,1), D(1,1)$, and $E\left(\left(R_{\mathrm{M} 0}-C_{\mathrm{M} 0}+L_{\mathrm{M}}\right) /\left(L_{\mathrm{M}}-R_{\mathrm{MC}+C_{\mathrm{MC}}}\right), \quad\left(R_{\mathrm{S} 0}-C_{\mathrm{S} 0}+L_{\mathrm{S}}\right) /\right.$ $\left.\left(L_{\mathrm{S}}-R_{\mathrm{SC}+C_{\mathrm{SC}}}\right)\right)$. The Jacobi matrix $J$ is as follows: $=\left((1-2 x)\left[\left(R_{\mathrm{SC}}-C_{\mathrm{SC}}-L_{\mathrm{S}}\right) y+R_{\mathrm{S} 0}-C_{\mathrm{S} 0}+L_{\mathrm{S}} x(1-x)\right.\right.$ $\left(\begin{array}{lll}R_{\mathrm{SC}} & C_{\mathrm{SC}}-L_{\mathrm{S}}\end{array} \quad y(1-y)\left(R_{\mathrm{MC}}-C_{\mathrm{MC}}-L_{\mathrm{M}} \gamma 1-2 y\right)\right.$ $\left.\left[\left(R_{\mathrm{MC}}-C_{\mathrm{MC}}-L_{\mathrm{M}}\right) x+R_{\mathrm{M} 0}-C_{\mathrm{M} 0}+L_{\mathrm{M}}\right]\right)$.

The above differential equations form a group dynamic system. Based on the construction of Jacobi matrix, the local stability of each equilibrium point is further discussed according to the symbolic changes in determinant and trace of Jacobi matrix under different conditions:

(1) When $R_{\mathrm{SC}}-C_{\mathrm{SC}}>0, R_{\mathrm{MC}}-C_{\mathrm{MC}}>0, R_{\mathrm{S} 0}-C_{\mathrm{S} 0}>$ 0 , and $R_{\mathrm{M} 0}-C_{\mathrm{M} 0}>0$, there are five equilibrium points in the system, including three unstable points, one locally asymptotical stable point, and one saddle point. When the equilibrium point of the system is $D(1,1)$, the Jacobi matrix of the system is as follows:

$$
J=\left(\begin{array}{cc}
C_{\mathrm{SC}}-R_{\mathrm{SC}}+C_{\mathrm{S} 0}-R_{\mathrm{S} 0} & 0 \\
0 & C_{\mathrm{MC}}-R_{\mathrm{MC}}+C_{\mathrm{M} 0}-R_{\mathrm{M} 0}
\end{array}\right)
$$

It is found that the $\lambda_{1}$ and $\lambda_{2}$ are both negative real parts. Therefore, point $D(1,1)$ is a locally asymptotically stable point; that is, the combination of (embedding, embedding) strategy is an evolutionarily stable strategy of the system. The practical significance of this evolutionary stabilization strategy lies in that when enterprise $\mathrm{S}$ and enterprise $\mathrm{M}$ embed in the supply chain network, and the network benefits they can obtain are greater than the network costs, and the cooperation benefits are greater than the cooperation costs; both enterprise $S$ and enterprise $M$ will gradually choose the embedding strategy to build the cooperative relationship between them. With the increasing networks and cooperation profit margins of enterprise $S$ and enterprise $M$, the possibility of both sides choosing the embedding strategy is greater. In addition, the symbols of determinants and traces of Jacobi matrices corresponding to each equilibrium point are shown in Table 5 .

(2) When $R_{\mathrm{SC}}-C_{\mathrm{SC}}+R_{\mathrm{S} 0}-C_{\mathrm{S} 0}<0$ and $C_{\mathrm{M} 0}-R_{\mathrm{M} 0}-$ $L_{\mathrm{M}}<0$, there are five equilibrium points in the system, including three unstable points, one locally asymptotical stable point, and one saddle point. When the equilibrium point of the system is $C(0,1)$, the Jacobi matrix of the system is as follows:

$$
J=\left(\begin{array}{cc}
R_{\mathrm{SC}}-C_{\mathrm{SC}}+R_{\mathrm{S} 0}-C_{\mathrm{S} 0} & 0 \\
0 & C_{\mathrm{M} 0}-R_{\mathrm{M} 0}-L_{\mathrm{M}}
\end{array}\right) .
$$

It is found that $\lambda_{1}$ and $\lambda_{2}$ are both negative real parts. Therefore, point $C(0,1)$ is a locally asymptotically stable point; that is, the combination of (nonembedding, embedding) strategy is an evolutionarily stable strategy of the system. The practical significance of this evolutionary stabilization strategy lies in that when enterprise $S$ embeds in the supply chain relationship network, the network gains are insufficient to compensate for the network costs it pays for, and the cooperative gains from cooperation between enterprise $S$ and enterprise $M$ are difficult to compensate for the investment cost of the dedicated assets it invests, or the overall network profit and cooperative profit are less than zero; the cooperative profit obtained with other member enterprises is larger than the difference between network cost and network profit; that is to say, the cooperative profit of enterprise $M$ is enough to compensate for the network loss or social liabilities caused by embedding in the supply chain network; the enterprise $S$ will gradually choose the nonembedding strategy, while enterprise $M$ will gradually choose the embedding strategy.

In addition, with the increasing sum of network loss and cooperation loss of enterprise $S$ and the difference between network cost, network profit, and cooperation profit, the more the possibility that enterprise $S$ will choose nonembedding strategy step by step is, and the more the probability that enterprise $M$ chooses embedding strategy is. In addition, the symbols of determinants and traces of Jacobi matrix corresponding to each equilibrium point are shown in Table 6 .

(3) When $C_{\mathrm{S} 0}-R_{\mathrm{S} 0}-L_{\mathrm{S}}<0, R_{\mathrm{MC}}-C_{\mathrm{MC}}+R_{\mathrm{M} 0}-C_{\mathrm{M} 0}<$ 0 , there are five equilibrium points in the system, including three unstable points, one locally asymptotical stable point, and one saddle point. When the 
TABLE 5: Local stability analysis of equilibrium points.

\begin{tabular}{lccc}
\hline Equilibrium point & Symbols of Jacobi matrix determinant & Symbols of Jacobi matrix traces & Local stability \\
\hline$A(0,0)$ & + & + & Instable \\
$B(1,0)$ & - & \pm & Instable \\
$C(0,1)$ & - & \pm & Instable \\
$D(1,1)$ & + & - & ESS \\
$E\left(x_{0}, y_{0}\right)$ & - & 0 & Saddle point \\
\hline
\end{tabular}

TABLE 6: Local stability analysis of equilibrium points.

\begin{tabular}{lccc}
\hline Equilibrium point & Symbols of Jacobi matrix determinant & Symbols of Jacobi matrix traces & Local stability \\
\hline$A(0,0)$ & + & + & Instable \\
$B(1,0)$ & \pm & \pm & Instable \\
$C(0,1)$ & + & - & ESS \\
$D(1,1)$ & \pm & \pm & Instable \\
$E\left(x_{0}, y_{0}\right)$ & - & 0 & Saddle point \\
\hline
\end{tabular}

equilibrium point of the system is $B(1,0)$, the Jacobi matrix of the system is as follows:

$$
J=\left(\begin{array}{cc}
C_{\mathrm{S} 0}-R_{\mathrm{S} 0}-L_{\mathrm{S}} & 0 \\
0 & R_{\mathrm{MC}}-C_{\mathrm{MC}}+R_{\mathrm{M} 0}-C_{\mathrm{M} 0}
\end{array}\right) .
$$

It is found that the $\lambda_{1}$ and $\lambda_{2}$ are both negative real parts. Therefore, point $B(1,0)$ is a locally asymptotically stable point; that is, the combination of (embedding, nonembedding) strategy is an evolutionarily stable strategy of the system. The practical significance of this evolutionary stabilization strategy lies in that when enterprise $\mathrm{M}$ embeds in the supply chain relationship network, the network gains are not enough to compensate for the network costs it pays for, and the cooperative gains from cooperation between enterprise $\mathrm{M}$ and enterprise $\mathrm{S}$ are difficult to compensate for the investment costs of the special assets it invests, or the overall network profits and cooperative profits are less than zero, while the cooperative profit obtained between enterprise $S$ and other manufacturers is larger than the difference between network cost and network profit; that is to say, the cooperative profit of enterprise $S$ is enough to compensate for the network loss or social liabilities caused by embedding in the supply chain network. Enterprise $\mathrm{M}$ will gradually choose the nonembedding strategy, while enterprise $S$ will gradually choose the embedding strategy. In addition, with the increasing sum of network loss and cooperation loss of enterprise $M$, the network cost and network profit, and the difference between cooperation profit of enterprise $S$, the possibility of enterprise $M$ choosing nonembedding strategy step by step is greater, and the probability of enterprise $S$ choosing embedding strategy is also greater. The symbols of determinants and traces of Jacobi matrix corresponding to each equilibrium point are shown in Table 7.

(4) When $R_{\mathrm{S} 0}-C_{\mathrm{S} 0}+L_{\mathrm{S}}<0$ and $R_{\mathrm{M} 0}-C_{\mathrm{M} 0}+L_{\mathrm{M}}<0$, there are five equilibrium points in the system, including three unstable points, one locally asymptotical stable point, and one saddle point. When the equilibrium point of the system is $A(0,0)$, the Jacobi matrix of the system is as follows:

$$
J=\left(\begin{array}{cc}
R_{\mathrm{S} 0}-C_{\mathrm{S} 0}+L_{\mathrm{S}} & 0 \\
0 & R_{\mathrm{M} 0}-C_{\mathrm{M} 0}+L_{\mathrm{M}}
\end{array}\right) .
$$

It is found that the $\lambda_{1}$ and $\lambda_{2}$ are both negative real parts. Therefore, point $A(0,0)$ is a locally asymptotically stable point; that is, the combination of (nonembedding, nonembedding) strategy is an evolutionarily stable strategy of the system. The practical significance of this evolutionary stabilization strategy lies in the following aspects. When the manufacturer chooses the nonembedding strategy, the total net profit obtained by the enterprise S embedding in the supply chain network and its cooperation profit with other manufacturers is not enough to compensate for the network cost. When the enterprise $S$ chooses the nonembedding strategy, the network profit and cooperation profit obtained by cooperation with other suppliers are not enough to compensate for the network cost, that is, the social liabilities formed by the enterprise $S$ or enterprise $M$ embedding in the supply chain relationship network separately. At the present, both enterprise $S$ and enterprise $M$ will gradually choose the nonembedding strategy more likely. Moreover, with the increasing gap between the network revenue, cooperative profit, and network cost of enterprise $S$ and enterprise $M$, the possibility of both sides gradually choosing the nonembedding strategy is greater. In addition, the symbols of determinants and traces of Jacobi matrix corresponding to each equilibrium point are shown in Table 8. 
TABLE 7: Local stability analysis of equilibrium points.

\begin{tabular}{lccc}
\hline Equilibrium point & Symbols of Jacobi matrix determinant & Symbols of Jacobi matrix traces & Local stability \\
\hline$A(0,0)$ & \pm & - & ESS \\
$B(1,0)$ & + & & \\
$C(0,1)$ & \pm & 0 & Saddle point \\
$D(1,1)$ & \pm & 0 & \\
$E\left(x_{0}, y_{0}\right)$ & - & & \\
\hline
\end{tabular}

TABLE 8: Local stability analysis of equilibrium points.

\begin{tabular}{lccc}
\hline Equilibrium point & Symbols of Jacobi matrix determinant & Symbols of Jacobi matrix traces & Local stability \\
\hline$A(0,0)$ & + & - & ESS \\
$B(1,0)$ & \pm & \pm & Instable \\
$C(0,1)$ & \pm & \pm & Instable \\
$D(1,1)$ & \pm & \pm & Instable \\
$E\left(x_{0}, y_{0}\right)$ & & 0 & Saddle point \\
\hline
\end{tabular}

(5) When $0<x_{0}, y_{0}<1$, the equilibrium point $E\left(x_{0}, y_{0}\right)$ is substituted into Jacobi matrix. The Jacobi matrix of the system is as follows:

$$
\begin{aligned}
J & =\left(\begin{array}{cc}
0 & J_{12} \\
J_{21} & 0
\end{array}\right), \\
J_{12} & =\frac{\left(R_{\mathrm{M} 0}-C_{\mathrm{M} 0}+L_{\mathrm{M}}\right)\left(C_{\mathrm{MC}}-R_{\mathrm{MC}}+C_{\mathrm{M} 0}-R_{\mathrm{M} 0}\right)\left(R_{\mathrm{SC}}-C_{\mathrm{SC}}-L_{\mathrm{S}}\right)}{\left(L_{\mathrm{M}}-R_{\mathrm{MC}}+C_{\mathrm{MC}}\right)^{2}}, \\
J_{21} & =\frac{\left(R_{\mathrm{S} 0}-C_{\mathrm{S} 0}+L_{\mathrm{S}}\right)\left(C_{\mathrm{SC}}-R_{\mathrm{SC}}+C_{\mathrm{S} 0}-R_{\mathrm{S} 0}\right)\left(R_{\mathrm{MC}}-C_{\mathrm{MC}}-L_{\mathrm{M}}\right)}{\left(L_{\mathrm{S}}-R_{\mathrm{SC}}+C_{\mathrm{SC}}\right)^{2}}, \\
\operatorname{det} J & =\left(-J_{12}\right) * J_{21}<0, \quad \text { and } \operatorname{tr} J=0 .
\end{aligned}
$$

Therefore, the equilibrium point $E\left(x_{0}, y_{0}\right)$ is not the asymptotic stability point of the system but the saddle point of the system.

From the analysis of the local stability of the above evolutionary game, we can draw the following conclusions: (1) when $y=y_{0}\left(0 \leq y_{0} \leq 1\right)$, the $F(x)=0$; that is, no matter how $x$ is selected within the definition range, the system will eventually reach an evolutionary stable state; when the proportion of manufacturers who adopt the embedding strategy is $y_{0}$, no matter which strategy the supplier chooses or how likely it is to adopt a certain strategy, there is no difference in earnings. When $x=x_{0}\left(0 \leq x_{0} \leq 1\right)$, there will always be $F(y)=0$; that is, no matter how $y$ is selected within the definition range, the system will eventually reach an evolutionary stable state; when the supplier proportion of choosing embedding strategy is $y_{0}$, no matter what strategy the manufacturer chooses or how likely it is to adopt, its benefits will be the same. (2) When $y>y_{0}$ and $y\left(R_{\mathrm{SC}}-C_{\mathrm{SC}}-L_{\mathrm{S}}\right)+\left(R_{\mathrm{S} 0}-C_{\mathrm{S} 0}+L_{\mathrm{S}}\right)>0, x=0$ and $x=1$ are two possible stabilization points. When $x=0, \partial F(x) / \partial x$ $=1>0$; while $x=1$ and $\partial F(x) / \partial x=-1<0$. Therefore, the evolutionary game will reach a stable state, and $x=1$ is the only possible stable point; that is, the supplier strategy will gradually shift from nonembedding to embedding, and embedding strategy will eventually become the evolutionary stable strategy of suppliers. Similarly, when $y<y_{0}, x=0$ is the only possible stability point; that is, the supplier strategy gradually shifts from embedding to nonembedding, and the nonembedding strategy will eventually become the evolutionary stability strategy of suppliers. (3) When $x>x_{0}$ and $x\left(R_{\mathrm{MC}}-C_{\mathrm{MC}}-L_{\mathrm{M}}\right)+\left(R_{\mathrm{M} 0}-C_{\mathrm{M} 0}+L_{\mathrm{M}}\right)>0, \quad y=0 \quad$ and $y=1$ are two possible stabilization points. When $y=0$, $\partial F(y) / \partial y=1>0$; while $y=1, \partial F(y) / \partial y=-1<0$. Therefore, the evolutionary game will reach a stable state. $y=1$ is the only possible stable point. That is, the strategy chosen by the manufacturer will gradually shift from nonembedding to embedding. Embedding strategy will eventually become the evolutionary stable strategy of the manufacturer. Similarly, when $x<x_{0}, y=0$ is the only possible stabilization point; that is, the strategy chosen by the manufacturer gradually shifts from embedding to nonembedding, the non-embedding strategy will eventually become the evolutionary stabilization strategy of the manufacturer. (4) Figure 5 shows that when point $(x, y)$ falls into the CEBD area, the system will converge to the ideal state in which both enterprise $S$ and enterprise $M$ choose the embedding strategy, while when 


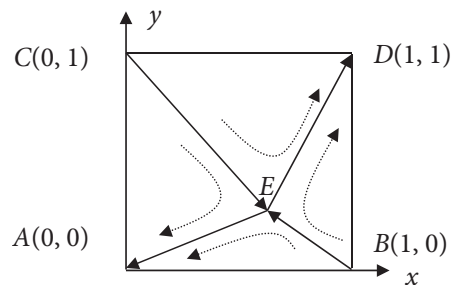

FIGURE 5: Phase diagram of evolutionary game equilibrium point.

point $(x, y)$ falls into the CEBA area, the result of evolutionary game will tend to the bad state that both sides adopt the nonembedding strategy.

\subsubsection{The Influence of Parameters Changing on Convergence} Rate. The group members participating in the game have the dynamic nature of optimum reaction with myopia. The initial state will influence the behavior pattern of the participants in the game in a conventional way and ultimately determines the direction of the group equilibrium strategy movement. The more the $E\left(x_{0}, y_{0}\right)$ approaches point $\mathrm{A}$, the larger the area of quadrilateral CEBD, which indicates that evolutionary game will converge to ideal state $\mathrm{D}$ gradually, that is, the more likely the enterprises $S$ and $M$ both choose the embedding strategy. The closer the $E\left(x_{0}, y_{0}\right)$ approaches point $\mathrm{D}$, the larger the area of quadrilateral CEBA, which indicates that evolutionary game will gradually converge to a bad "lock-in" state, that is, the more likely both enterprises S and enterprise $M$ will choose nonembedding strategy.

Under normal circumstances, the higher the network revenue $\left(R_{\mathrm{S} 0}, R_{\mathrm{M} 0}\right)$ and cooperation revenue $\left(R_{\mathrm{SC}}, R_{\mathrm{MC}}\right)$ can be obtained by suppliers and manufacturers embedding in the supply chain network, the closer the saddle point $E\left(x_{0}, y_{0}\right)$ moves towards point $A(0,0)$ on online $\mathrm{AED}$, and the larger the area of quadrilateral CEBD; the system is more conducive to the ideal stable state, and the probability of both suppliers and manufacturers choosing embedding strategy increases. On the contrary, the higher the cooperation cost $\left(C_{\mathrm{SC}}, C_{\mathrm{MC}}\right)$ and investment cost $\left(C_{\mathrm{S} 0}, C_{\mathrm{M} 0}\right)$ paid by supplier and manufacturer because of embedding in supply chain relationship network, the closer the saddle point $E\left(x_{0}, y_{0}\right)$ moves towards point $D(1,1)$ on online AED, and relatively the larger the area of quadrilateral CEBA, so the system will gradually converge to a bad "lock-in" state; that is, the probability of supplier and manufacturer both choosing nonembedding strategy increases. Therefore, suppliers and manufacturers can effectively improve the cooperation revenue between the two sides by improving production efficiency and reducing transaction costs, thus speeding up the convergence of evolutionary game to an ideal state. In addition, when one side chooses nonembedding strategy, the higher the cooperative profits $\left(L_{S}, L_{\mathrm{M}}\right)$ obtained by the other side cooperating with other member enterprises, the more the saddle point $E\left(x_{0}, y_{0}\right)$ tends to move towards point $D(1$, 1 ), which is not conducive to the ideal stable state of the system; on the contrary, it promotes the system to converge gradually to the bad "lock-in" state.
3.2.6. Game Simulation Experiment of Vertical Enterprises. In view of the fact that supplier and manufacturer enterprises occupy different network positions and have different network powers in the supply chain network, this paper assigns the parameters affecting their embedding behavior according to the operation practice of supply chain enterprises. This paper assumes that manufacturer enterprises are at the core of supply chain relationship network, so they need to pay higher $C_{\mathrm{M} 0}$ and $C_{\mathrm{MC}}$ than supplier enterprises. In addition, the cost of cooperation between supplier $S$ or manufacturer $M$ and other supply chain enterprises is higher than that between them.

For the sake of simplicity and generality, this paper sets the network return rate of supplier enterprise $S$ as $r_{\mathrm{S} 0}$, and then, the network returns $R_{\mathrm{S} 0}=\left(1+r_{\mathrm{S} 0}\right) C_{\mathrm{S} 0}$; the return rate of supplier enterprise $S$ cooperating with other manufacturers is $r_{S}$, and then, the profit of supplier enterprise $S$ cooperating with other manufacturers is $L_{\mathrm{S}}=\left(1+r_{\mathrm{S}}\right) C_{\mathrm{S}}$; the return rate of supplier enterprise $S$ cooperating with manufacturer enterprise $\mathrm{M}$ is $r_{\mathrm{SC}}$, and then, the profit of supplier $\mathrm{S}$ cooperating with manufacturer $\mathrm{M}$ is $R_{\mathrm{SC}}=\left(1+r_{\mathrm{SC}}\right) C_{\mathrm{SC}}$. Similarly, this paper sets the network return rate of manufacturer enterprise $\mathrm{M}$ as $r_{\mathrm{M} 0}$, and then, the network return is $R_{\mathrm{M} 0}=\left(1+r_{\mathrm{M} 0}\right) C_{\mathrm{M} 0}$; the return rate of supplier enterprise $\mathrm{S}$ cooperating with other manufacturer enterprises is $r_{\mathrm{M}}$, and then, the profit of supplier enterprise $S$ cooperating with other manufacturer enterprises is $L_{\mathrm{M}}=\left(1+r_{\mathrm{M}}\right) C_{\mathrm{M}}$; and the return rate of supplier enterprise $\mathrm{S}$ cooperating with manufacturer enterprise $\mathrm{M}$ is $r_{\mathrm{MC}}$, and then, the cooperation profit of supplier enterprise $S$ and manufacturer enterprise $M$ is $R_{\mathrm{MC}}=\left(1+r_{\mathrm{MC}}\right) C_{\mathrm{MC}}$. On this basis, the new replicated dynamic differential equations $F(x)$ and $F(y)$ are obtained. The initial values of the parameters are set as shown in Table 9.

Based on the initial values of the above parameters, the network embedding behavior strategy of supply chain enterprises is simulated by using MATLAB simulation software. As shown in Figure 6, the proportion of supplier $S$ and manufacturer $M$ choosing to embed in the supply chain relationship network will eventually converge to 1, and thus, the system will reach an ideal evolutionary stable state. In addition, compared with the supplier enterprise $S$, the manufacturer $M$ will achieve an ideal stable state with a faster convergence rate. With the increasing $x$ value, more and more suppliers choose embedding strategy, and manufacturers tend to quickly adjust their own strategy and embed in the supply chain relationship network; similarly, with the increasing $y$ value, more and more manufacturers choose embedding strategy, and supplier enterprises will also pay attention to market changes, adjust their own strategy in time, and choose to embed in supply chain networks. Generally speaking, when the other party's behavior strategy is established, the manufacturer's response time to external environmental changes is relatively short and has a strong sensitivity.

As shown in Figure 7, the initial value of $r_{\mathrm{SC}}$ between supplier $S$ and manufacturer $M$ is changed from 0.5 to 0.25 and 0.75 , respectively, and different simulation results are obtained. When the cooperative return rate between supplier enterprise $S$ and manufacturer enterprise $M$ decreases, that is, $r_{\mathrm{SC}}=0.25$, the proportion of supplier enterprise 
TABLE 9: Initial values of parameters and implications.

\begin{tabular}{lcc}
\hline Parameter name & Initial value & Parameter implication \\
\hline$r_{\mathrm{S} 0}$ & 0.1 & Network return rate of $\mathrm{S}$ \\
$r_{\mathrm{S}}$ & 0.25 & Cooperative return rate between $\mathrm{S}$ and others \\
$r_{\mathrm{SC}}$ & 0.5 & Cooperative return rate between $\mathrm{S}$ and $\mathrm{M}$ \\
$C_{\mathrm{S} 0}$ & 1 & Special assets investment cost of $\mathrm{S}$ \\
$C_{\mathrm{SC}}$ & 2 & Cooperation cost between $\mathrm{S}$ and $\mathrm{M}$ \\
$C_{\mathrm{S}}$ & 4 & Cooperation cost between $\mathrm{S}$ and others \\
$r_{\mathrm{M} 0}$ & 0.2 & Network return rate of $\mathrm{M}$ \\
$r_{\mathrm{M}}$ & 0.35 & Cooperative return rate between $\mathrm{M}$ and others \\
$r_{\mathrm{MC}}$ & 0.6 & Cooperative return rate between $\mathrm{M}$ and $\mathrm{M}$ \\
$C_{\mathrm{M} 0}$ & 2 & Special assets investment cost of $\mathrm{M}$ \\
$\mathrm{C}_{\mathrm{MC}}$ & 3 & Cooperation cost between $\mathrm{M}$ and $\mathrm{S}$ \\
$C_{\mathrm{M}}$ & 5 & Cooperation cost between $\mathrm{M}$ and others \\
\hline
\end{tabular}

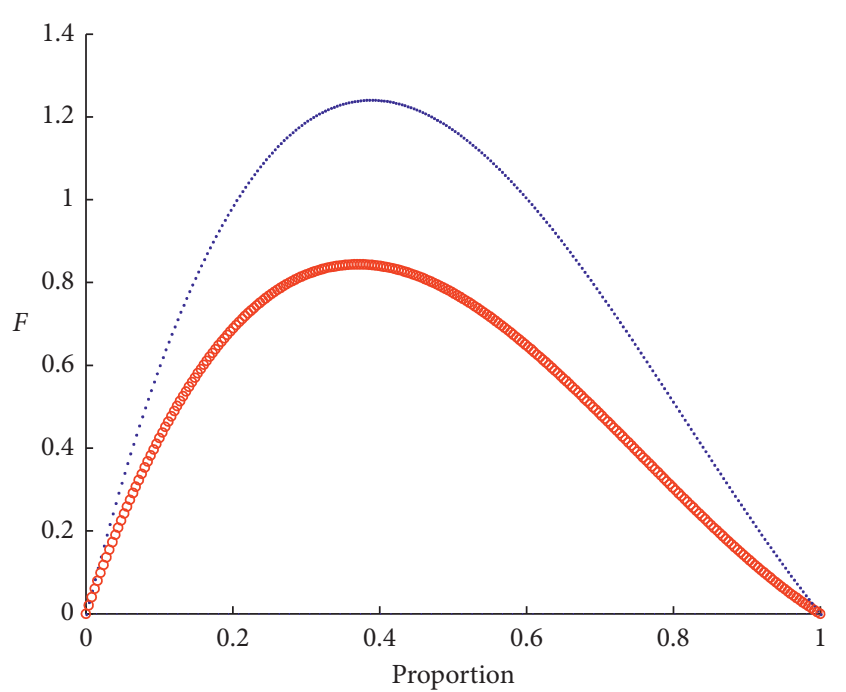

$\circ x$

$y$

Figure 6: Initial simulation results.

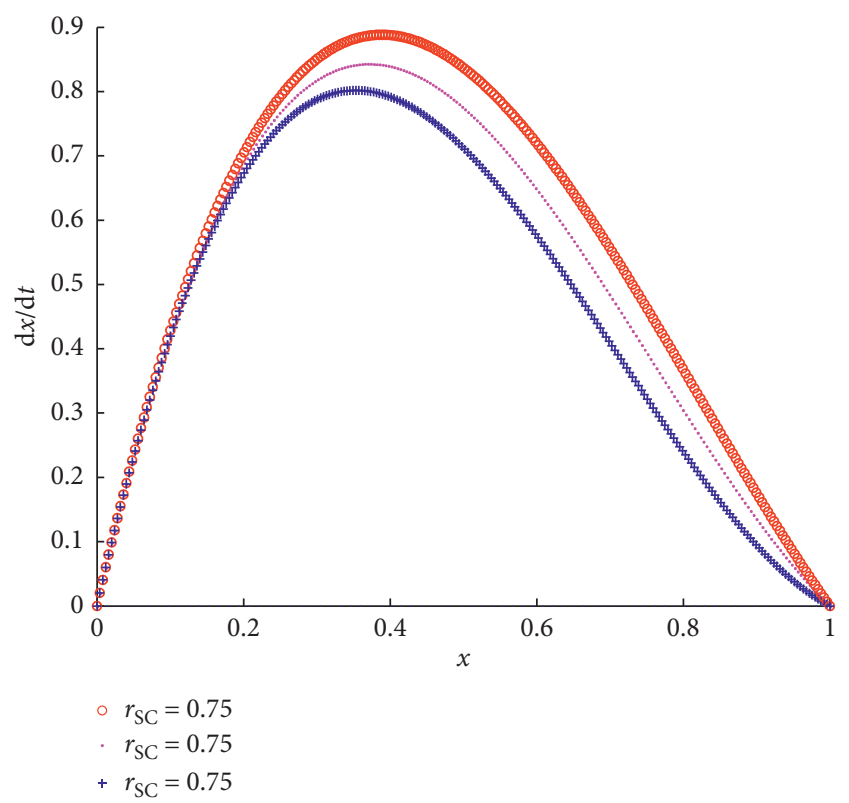

Figure 7: Analysis of simulation test results 1. choosing the embedding strategy decreases, and the sensitivity to external environment changes also decreases. When the cooperative return rate between supplier enterprise $S$ and manufacturer enterprise $M$ increases, that is, $r_{\mathrm{SC}}=0.75$, the proportion of supplier enterprise choosing the embedding strategy is increased, and the sensitivity to external environmental changes is also improved. Thus, the higher the cooperative return rate between supplier enterprise $S$ and manufacturer enterprise $M$ is, the larger the proportion of supplier enterprise choosing the embedding strategy is. That is, when supplier enterprise perceives it is more profitable to embed in supply chain relationship network, the more likely it is to choose the embedding strategy.

Similarly, as shown in Figure 8, the initial value of $r_{\mathrm{MC}}$ between manufacturer $M$ and supplier $S$ is changed from 0.6 to 0.4 and 0.8 , respectively, and different simulation results are obtained. When the cooperative return rate between manufacturer $\mathrm{M}$ and supplier $\mathrm{S}$ decreases, that is, $r_{\mathrm{MC}}=0.4$, the proportion of manufacturer enterprises choosing the embedding strategy decreases, and the sensitivity to external environment changes also decreases. When the cooperative return rate between manufacturer $M$ and supplier $S$ increases, that is, $r_{\mathrm{MC}}=0.8$, manufacturer enterprises choose the embedding strategy. The proportion is slightly increased, and the sensitivity to changes in the external environment is also improved. Thus, the higher the cooperative return rate between manufacturer $M$ and supplier $S$ is, the greater the proportion of manufacturer enterprises choosing the embedding strategy is. That is, when manufacturer enterprises perceive embedding in supply chain relationship network and cooperating with supplier enterprises more profitably, the more likely they choose the embedding strategy.

In addition, in order to further explore the dynamic trend of vertical enterprises' embedding behaviors in supply chain, this paper set $m_{1}=R_{\mathrm{SC}}-C_{\mathrm{SC}}-L_{\mathrm{S}}$, $m_{2}=R_{\mathrm{S} 0}-C_{\mathrm{S} 0}+L_{\mathrm{S}}, \quad m_{3}=R_{\mathrm{MC}}-C_{\mathrm{MC}}-L_{\mathrm{M}}, \quad$ and $m_{4}=R_{\mathrm{M} 0}-C_{\mathrm{M} 0}+L_{\mathrm{M}}$, and $C_{11}$ and $C_{12}$ are the initial values of $x$ and $y$, respectively. The initial values of parameters are set as shown in Table 10.

As shown in Figure 9, picture coding (1), (2), (6), (9), and (10) show that although the proportion of enterprises choosing to embed in the supply chain relationship network fluctuates near the value 1 , it will converge to 1 with the change in time $t$. Thus, 


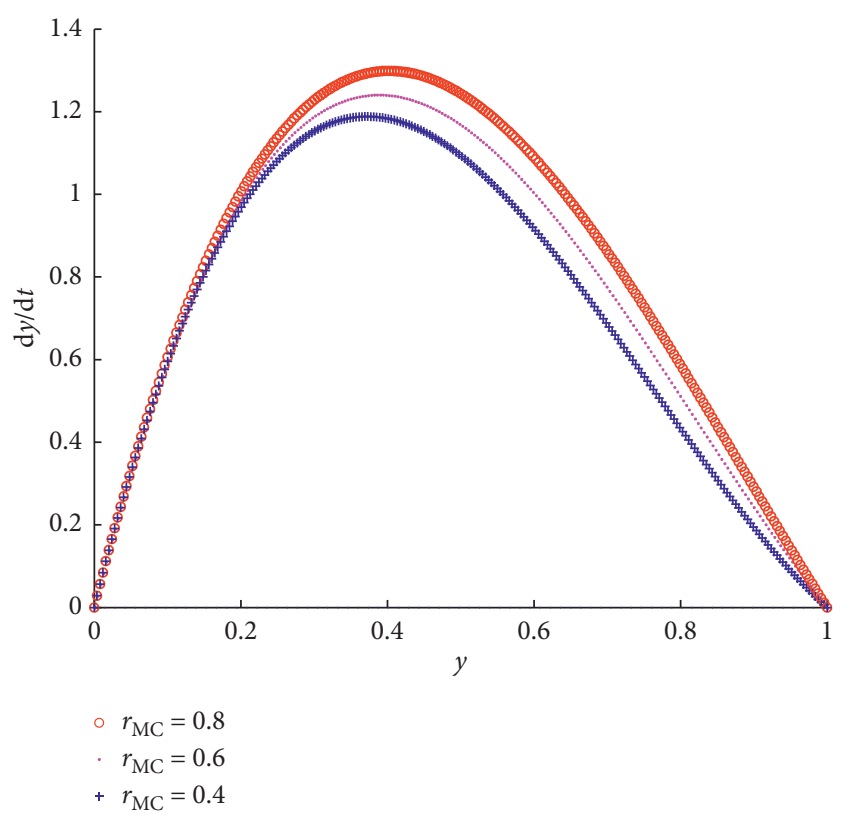

Figure 8: Analysis of simulation test results 2.

TABLE 10: Initial parameters of vertical enterprise.

\begin{tabular}{lccccr}
\hline Picture coding & $m_{1}$ & $m_{2}$ & $m_{3}$ & $m_{4}$ & $C_{11}$ \\
\hline (1) & 200 & 200 & 400 & 200 & 0.99 \\
(2) & 1.20 & 1 & 1 & 2 & 0.50 \\
(3) & 1 & -1 & 2 & -1 & 0.01 \\
(4) & -100 & -100 & -200 & -200 & 0.50 \\
(5) & -100 & 100 & -200 & 200 & 0.01 \\
(6) & -100 & -100 & 2 & 2 & 0.05 \\
(7) & 0.10 & -0.20 & 0.02 & 0.05 & 0.01 \\
(8) & 0.10 & 0.20 & 0.20 & 0.01 \\
(9) & -0.10 & -0.20 & -0.20 & 0.20 & 0.05 \\
(10) & 0.10 & 0.20 & -0.20 & 0.05 & 0.01 \\
\hline
\end{tabular}

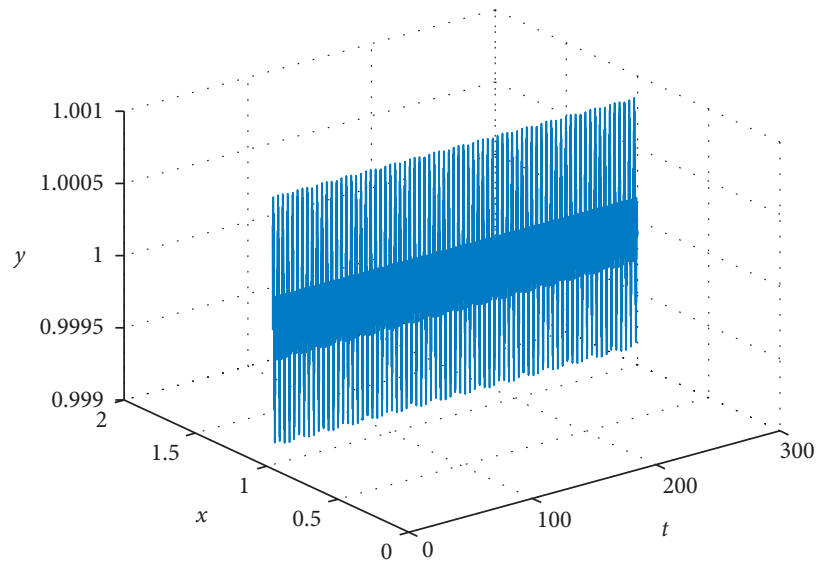

(a)

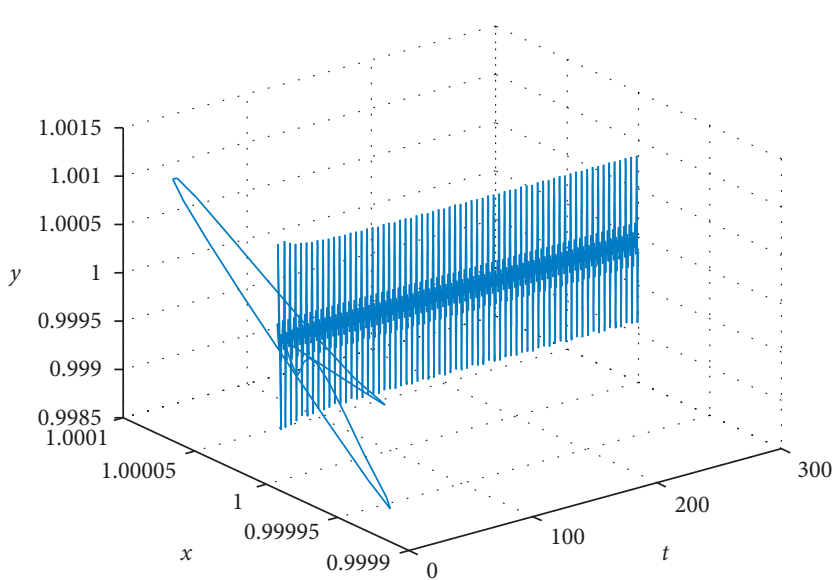

(b)

Figure 9: Continued. 


$$
-=
$$




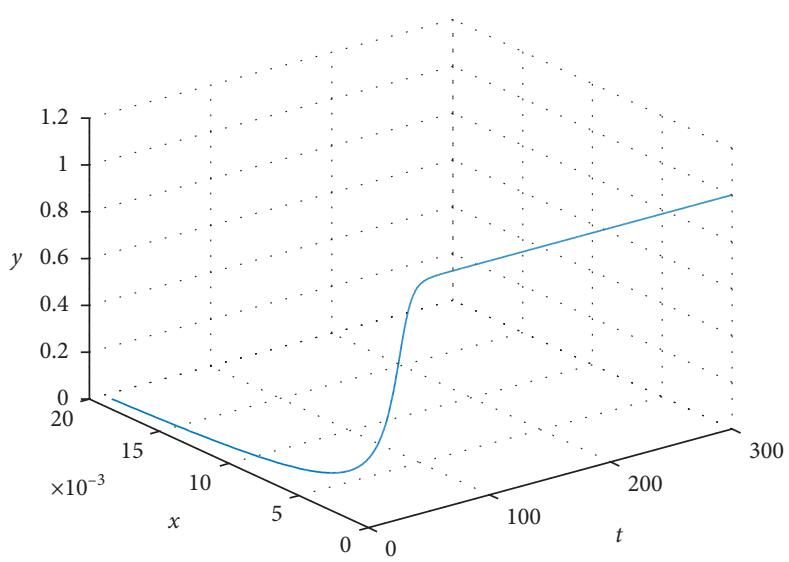

(i)

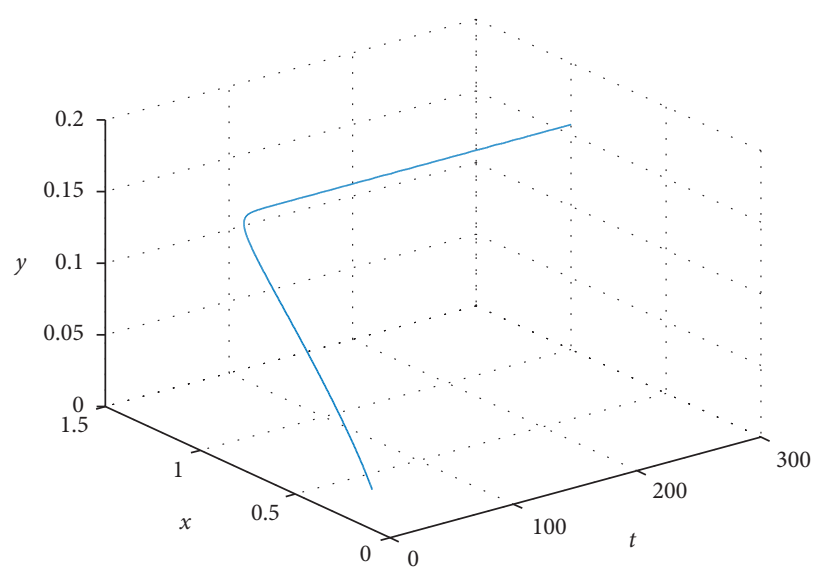

(j)

FIGURE 9: Simulated graph of vertical enterprises: (a) (1); (b) (2); (c) (3); (d) (4); (e) (5); (f) (6; (g) (7); (h) (8); (i) (9); (j) (10).

the system achieves an ideal evolutionary stable state; that is, $x=1$ is the evolutionary stable point, and the embedding strategy is the evolutionary stable strategy.

While picture coding (3), (4), (5), (7), and (8) show that although the proportion of enterprises choosing to embed in the supply chain relationship network oscillates near the value 0 , it will eventually converge to 0 with the change in time $t$; thus, the system achieves an ideal evolutionary stable state; that is, $x=0$ is the evolutionary stable point, and the nonembedding strategy is the evolutionary stable strategy. Thus, although the initial values and parameters of $x$ and $y$ are different, the system will eventually stabilize at the equilibrium point of $x=0$ or $x=1$ with the time-varying periodicity.

In summary, based on the external dynamic environment, enterprises often choose to embed in the supply chain relationship network, seek to sign cooperation contracts with other member enterprises and establish partnerships, so as to obtain more heterogeneous resources and information from the supply chain relationship network, and overcome the resource constraints. By speeding up the crossborder flow of capital and information in the supply chain network, supply chain enterprises can promote mutual cooperation among enterprises and develop more innovative products or services to meet the needs of the individualized and diversified market in order to realize the benefit sharing and performance improvement among enterprises.

\section{Conclusion and Enlightenment}

Based on the dynamic evolutionary game method, this paper clarifies the path evolution direction, law, and dynamic convergence process of supply chain enterprise's network embedding strategy selection. The conclusions of this paper mainly include the following two aspects.

On the one hand, whether supply chain enterprises adopt network embedding behavior is related to such factors as investment cost of special assets, cooperation cost, network income, cooperation income, cooperation profit with other member enterprises, and the probability of other member enterprises choosing embedding behavior. The greater the network profit that enterprises gain when they embed in the supply chain network is, the greater the possibility of enterprises choosing the embedding strategy is. The greater the cooperative profit obtained by cooperation among enterprises is, the greater the possibility of enterprises choosing the embedding strategy is. When the cooperative profit between enterprises is obviously larger than the cooperative profit between one enterprise and other enterprises, enterprises will choose the embedding strategy with the increase in the difference more likely.

On the other hand, the evolutionary results of strategic decision-making behavior of supply chain enterprises may or may not be the embedding strategy. The result of this evolution depends on the value of interfirm cooperative profits and the net profit of enterprises and whether the sum of the profits of interfirm cooperation with other member enterprises can compensate for the embedding cost of enterprises. With the constant changes in parameters such as initial values and time $t$, the system will eventually converge to 1 and reach an ideal evolutionary stable state; that is, $x=1$ is the evolutionary stable point, and the embedding strategy is the evolutionary stable strategy; or if the system will eventually converge to 0 , the system can reach an ideal evolutionary stable state; that is, $x=0$ is the evolutionary stable point, and the nonembedding strategy is the evolutionary stable strategy.

Therefore, under the condition that other factors remain unchanged, supply chain enterprises should reduce the investment cost and cooperation cost of special assets and realize the maximization of network revenue and cooperation income, so as to improve the possibility of adopting network embedding behavior. In addition, the enterprises should narrow the gap between the extra-cooperation profit and the current cooperation profit obtained by cooperation between supply chain enterprises and other member enterprises and restrain supply chain enterprises from violating the cooperation contract and taking opportunistic actions in order to increase the probability of choosing network embedding behavior. 
In conclusion, by constructing the game model of network embedding behavior of horizontal and vertical enterprises in the supply chain, this paper clarifies the evolution direction and law of network embedding strategy selection of enterprises, discusses the stable state and dynamic convergence process of evolutionary game, and provides a reference for the enterprises' decision-making of network embedding behaviors. However, there are still a few shortcomings and deficiencies remaining. For example, this paper only discusses the factors that affect the enterprises' network embedding behaviors from two aspects of cost and benefit, ignoring the influence of external factors such as environment. In the future, we should fully consider the influence of external environmental factors on the enterprises' behaviors choosing to embed the supply chain network and the cooperation with other node enterprises and reconstruct the network embedding behavior model of supply chain enterprises. In addition, the supply chain network is more complex in reality, including multiple participants. In the future research, the supply chain network structure can be extended to the situation of one supplier (manufacturer, retailer) to multiple manufacturers (retailer) or even multiple suppliers (manufacturer, retailer) to multiple manufacturers (retailer) when constructing the supply chain enterprises' embedded behavior model in order to make it more realistic.

\section{Data Availability}

The data used to support the findings of this study are available from the corresponding author upon request.

\section{Conflicts of Interest}

The authors declare that they have no conflicts of interest.

\section{Acknowledgments}

This paper was supported by the General Projects of the National Social Science Fund (Research on industrial chain synergy mechanism of new type agricultural operators under high quality development target (19BGL150)) and Social Science Youth Project of Shandong Province (Research on the sustainable growth mechanism of farmers' professional cooperatives in Shandong Province from the perspective of network embeddedness (20DGLJ08)).

\section{References}

[1] F. H. Zhang and T. Y. Zuo, "Network embeddedness and innovation performance of domestic firms under the circumstance of fdi clustering," R\&D Management, vol. 25, no. 5, pp. 70-80, 2013.

[2] H. J. Xiao, "Shared value," Business Ecosphere and the Transformation of Competitive Paradigms for Business Reform, vol. 17, pp. 129-141, 2015.

[3] S. L. Vargo and R. F. Lusch, "Service-dominant logic: continuing the evolution," Journal of the Academy of Marketing Science, vol. 36, no. 1, pp. 1-10, 2008.

[4] Y. Du and H. Zhang, "Research on the impact of the use of channel power on channel cooperation in the flower market-taking relationship commitment as adjustment," Variable Review of Economy and Management, vol. 33, no. 1, pp. 65-74, 2017.

[5] L. Xie, J. Ma, and H. Han, "Implications of stochastic demand and manufacturers' operational mode on retailer's mixed bundling strategy and its complexity analysis," Applied Mathematical Modelling, vol. 55, no. 3, pp. 484-501, 2018.

[6] J. Ma and H. Wang, "Complexity analysis of dynamic noncooperative game models for closed-loop supply chain with product recovery," Applied Mathematical Modelling, vol. 38, no. 23, pp. 5562-5572, 2014.

[7] J. Ma and X. Ma, "Measure of the bullwhip effect considering the market competition between two retailers," International Journal of Production Research, vol. 55, no. 2, pp. 313-326, 2017.

[8] X. Su and H. Zhang, "Research on the governance of agricultural product channel relations from the perspective of tripartite game," Journal of Agro-Technical Economics, vol. 36, no. 3, pp. 42-52, 2017.

[9] X. J. Pu and D. L. Jin, "The operational efficiency measurement of agro-food supply chains: the single farmer-supermarket direct purchase vs," Dual Channel Chinese Journal of Management Science, vol. 25, no. 1, pp. 98-105, 2017.

[10] M. K. He and W. J. Wang, "International reference and China s strategies for the development of modern supply chain," Reform, vol. 31, no. 1, pp. 22-35, 2018.

[11] H. M. Liu, Y. Wang, and H. J. Li, "The impact of partnership and logistics capability on," Supply Chain Integration Chinese Journal of Management Science, vol. 24, no. 12, pp. 148-157, 2016.

[12] Y. Lin, "Is downstream the knowledge source for technological innovations," Studies in Science of Science, vol. 35, no. 3, pp. 471-479, 2017.

[13] M. Xue, "The Influence of Supply Chain Partner Characteristics on Supply Chain Financing in Perspective of Network Capacity Variance," Intermediary Role of Relational Capital Management Review, vol. 30, no. 6, pp. 238-250, 2018.

[14] G. Q. Chen, Supply Chain Management China Soft Science, vol. 10, pp. 101-104, 1999.

[15] A. Surana, S. Kumara, M. Greaves, and U. N. Raghavan, "Supply-chain networks: a complex adaptive systems perspective," International Journal of Production Research, vol. 43, no. 20, pp. 4235-4265, 2005.

[16] S. H. Ma, "The influence of core enterprise on the formation of strategic partnership in supply chain," Industrial Engineering and Management, vol. 5, no. 1, pp. 24-27, 2000.

[17] C. L. Feng, "Research on the relationship between supply chain knowledge sharing and firm performance: the mediating and moderating effect of Supply Chain," Agility and Environmental Dynamics Management Review, vol. 27, no. 11, pp. 181-191, 2015.

[18] J. Ma and L. Sun, "Complexity analysis about nonlinear mixed oligopolies game based on production cooperation," IEEE Transactions on Control Systems Technology, vol. 26, no. 4, pp. 1532-1539, 2018.

[19] K. D. Zhou, Enterprise Economics China Prospect, Publishing House, China, 1987.

[20] T. Neil, A. James, and B. Cecil, "A framework for understanding managerial responses to supply chain complexity," International Journal of Operations \& Production Management, vol. 38, no. 6, pp. 1443-1466, 2018.

[21] H. Q. Hu, "Research on the mechanism of relational capital s effect on supply chain financing from the perspective of 
complex supply chain," Network Management Review, vol. 31, no. 12, pp. 306-318, 2019.

[22] E. M. Tachizawa and C. Y. Wong, "The performance of green supply chain management governance mechanisms: a supply network and complexity perspective," Journal of Supply Chain Management, vol. 51, no. 3, pp. 18-32, 2015.

[23] K. Polanyi, The Great Transformation: Economic and Political Origins of Our Time, Rinehart, New York, NY, USA, 1944.

[24] M. Granovetter, "Economic action and social structure: the problem of embeddedness," American Journal of Sociology, vol. 91, no. 3, pp. 481-510, 1985.

[25] B. Uzzi, "Social structure and competition in interfirm networks: the paradox of embeddedness," Administrative Science Quarterly, vol. 42, no. 1, pp. 35-67, 1997.

[26] H. James and K. Johan, "Multilevel embeddedness: the case of the global fisheries governance complex," Social Networks, vol. 44, no. 1, pp. 281-294, 2016.

[27] C. Y. Zhang, T. Guo, and H. D. Liu, "The impact of network embedding on the business mode innovation of technological," Entrepreneurship Studies in Science of Science, vol. 36, no. 1, pp. 167-175, 2018.

[28] M. C. Dong, F. Zeng, and C. Su, "Network embeddedness as a dependence-balancing mechanism in developing markets: differential effects for channel partners with asymmetric dependencies," Journal of the Academy of Marketing Science, vol. 47, no. 6, pp. 1064-1084, 2019.

[29] X. Xie, H. Wang, and H. Jiao, "Non-R\&D innovation and firms' new product performance: the joint moderating effect of R\&D intensity and network embeddedness," R\&D Management, vol. 49, no. 5, pp. 748-761, 2019.

[30] L. Tanja, C. Sylvie, and D. Pavlos, "Network embeddedness in the internationalization of biotechnology entrepreneurs," Entrepreneurshipe Regional Development, vol. 30, no. 3, pp. 1-23, 2018.

[31] S. L. Zhu and Y. Z. Chen, "Reverse embedding, parenting control and overseas innovation of Chinese enterprises," Document Review and Future Reform of Economic System, vol. 35, no. 2, pp. 94-99, 2017.

[32] B. Yang and Y. Yang, "Postponement in supply chain risk management: a complexity perspective," International Journal of Production Research, vol. 48, no. 7, pp. 1901-1912, 2010.

[33] M. Erica, P. Giovanni, and S. K. Dzidziso, "Network embeddedness and new product development in the biopharmaceutical industry: the moderating role of open innovation flow," International Journal of Production Economics, vol. 160, no. 2, pp. 106-119, 2015.

[34] J. P. Xie, H. W. Kong, and W. S. Zhang, "S \& T innovation platform: network characteristics, operation governance and development strategy-a case study from $S$ \& $T$ innovation practice of zhongguancun and," ZhangjiangPark Business Management Journal, vol. 39, no. 5, pp. 36-49, 2017.

[35] G. R. Chai, "Evolutionary game analysis on the cooperative behavior in industrial cluster under supply chain," Networks Science Research Management, vol. 32, no. 5, pp. 129-134, 2011.

[36] J. Ma, W. Lou, and Y. Tian, "Bullwhip effect and complexity analysis in a multi-channel supply chain considering price game with discount sensitivity," International Journal of Production Research, vol. 57, no. 17, pp. 5432-5452, 2019.

[37] J. Ma and L. Xie, “The stability analysis of the dynamic pricing strategy for bundling goods: a comparison between simultaneous and sequential pricing mechanism," Nonlinear Dynamics, vol. 95, no. 2, pp. 1147-1164, 2019.
[38] J. Ma and L. Xie, "The stability analysis of the dynamic pricing strategy for bundling goods: a comparison between simultaneous and sequential pricing mechanism," Nonlinear Dynamics, vol. 95, no. 2, pp. 1147-1164, 2019.

[39] T. F. Nie, B. Y. He, and S. F. Du, "Supply chain operations considering fairness concerns with bargaining disagreement point," Journal of Management Sciences in China, vol. 20, no. 10, pp. 92-102, 2017.

[40] P. Sun, "Co-evolution mechanism and countermeasures of B2C," Logistics Service Supply Chain, vol. 38, no. 12, pp. 93-96, 2019.

[41] J. Jian, Y. Guo, L. Jiang, Y. An, and J. Su, "A multi-objective optimization model for green supply chain considering environmental benefits," Sustainability, vol. 11, no. 21, p. 5911, 2019.

[42] J. Jian, Y. Zhang, L. Jiang, and J. Su, "Coordination of supply chains with competing manufacturers considering fairness concerns," Complexity, vol. 2020, Article ID 4372603, 15 pages, 2020. 